DAVID M. CUTLER

Massachusetts Institute of Technology

JAMES M. POTERBA

Massachusetts Institute of Technology

LOUISE M. SHEINER

Harvard University

LAWRENCE H. SUMMERS

Harvard University

\title{
An Aging Society: Opportunity or Challenge?
}

AN AMERICAN woman reaching childbearing age in 1960 would expect 3.6 children; an identical woman in 1990 would expect only 1.9 children. That dramatic demographic change makes it almost inevitable that the American population will age rapidly over the next 50 years. By 2025, the share of the American population that is 65 or older will exceed the share of Florida's population that is of retirement age today. The ratio of retirees to workers will have risen by nearly two-thirds. Even more dramatic demographic changes are occurring abroad. The share of the Japanese population that is 65 or over will rise from 11 percent to 19 percent over the next two decades. If current fertility levels in West Germany are maintained until 2050 , the population will not only age but shrink more than one-third.

These demographic changes have aroused considerable anxiety in the United States. Economic concerns have focused on the burden that a

We are grateful to George Akerlof, Robert Barro, Greg Duffee, Rachel Friedberg, Ken Judd, Larry Katz, Laurence Kotlikoff, Julio Rotemberg, Robert Solow, and members of the Brookings Panel for helpful comments and to the National Science Foundation and Alfred P. Sloan Foundation for research support. A data appendix for this project is on file at the Inter-university Consortium for Political and Social Research in Ann Arbor, MI. 
growing elderly population will place on the economy in general and the federal treasury in particular, as well as on a possible loss of dynamism as population growth slows. Those concerns have led to a potentially radical change in American fiscal policy. To ensure that social security taxes will be sufficient to fund benefits over the next 75 years, and to help the nation save in anticipation of increased demographic burdens, the social security legislation enacted in 1983 calls for social security taxes to exceed benefits over the next 30 years. This surplus will be accumulated in a trust fund, which will peak at 29 percent of GNP in 2020 and then be drawn down as the population ages.

This paper steps back from the current political debate over the social security trust fund and examines the more general question of how serious a macroeconomic problem aging is and how policy should respond to it. We focus primarily on issues relating to saving and capital accumulation. We do not consider the broader question of whether the current U.S. national saving rate is too high or too low, but focus on the effect of demographic changes on the optimal level of national saving. In addition, we consider the effects of demographic change on productivity growth and the optimal timing of tax collections.

Our general conclusion is that demographic changes will improve American standards of living in the near future, but lower them slightly over the very long term. Other things being equal, the optimal policy response to recent and anticipated demographic changes is almost certainly a reduction rather than an increase in the national saving rate. Slowing population growth will reduce the investment that must be devoted to equipping new workers and housing new families, while making it easier for the United States to attract foreign capital. Although there are many reasons for arguing that the United States currently saves too little, anticipated demographic change is not one of them.

Our analysis proceeds in five steps. First, we assess the coming dependency burden. While it is true that the share of the population aged 65 or over will increase sharply, it is also true that the share of children in the population will gradually decline, and that the fraction of the labor force that is near peak productivity will increase. Using information on projected fertility, mortality, and labor force participation rates as well as data on health care costs and the spending of different age groups, we assess past and future dependency trends. We find that demographic changes unaccompanied by changes in capital intensity would reduce 
per capita incomes by between 7 percent and 12 percent over the next 60 years, but would actually increase incomes over the next 20 years. In only one of the next six decades will demographic changes affect living standards as much as the "peace dividend" is likely to affect them in this decade. The decline in living standards caused by the increased dependence would be fully reversed by a 0.15 percent a year increase in productivity growth.

Second, we consider the consequences of the slower labor force growth that presages the increase in the retired share of the population. Between 2010 and 2060, the labor force is expected to decline slightly, compared with an average increase of 1.5 percent annually between 1950 and 1990. The projected decline in the labor force growth rate will permit a 3-4 percent reduction in the share of net investment in total income without reducing capital intensity. Since reduced labor force growth will occur before dependency burdens increase, projected demographic changes raise the short-term consumption path even if the steady-state consumption level declines. We show that in a standard growth model with plausible parameter values, optimal consumption typically rises in response to a demographic shock like that experienced in the United States over the past three decades.

Third, we consider the implications of integrated world capital markets for our analysis. The degree and speed of population aging in other major industrialized countries, particularly West Germany and Japan, is more dramatic than that in the United States. The increase in dependency abroad will coincide with a deceleration in labor force growth rates. Along an optimal path, therefore, the rest of the world will export capital to the United States-thus increasing U.S. consumption and reducing saving in the short run.

Fourth, we go beyond the standard growth theoretic approach and ask whether the coming demographic changes are likely to affect the rate of technical change. With slow labor force growth, labor is scarce; this scarcity may induce more rapid technical change. Such a development would sharpen our conclusion that diminished fertility represents an opportunity rather than a problem. Using international cross-section time series data for $1960-85$, we find some evidence that nations with slower labor force growth do experience more rapid productivity growth. The estimates suggest that the reduction in labor force growth projected for the next 40 years may raise productivity growth enough to offset 
fully the consequences of increased dependence. This finding, however, is uncertain. A more definitive finding is the absence of any empirical support for the pessimistic view that aging societies suffer reduced productivity growth.

Fifth, we consider the implications of our findings for fiscal policy. Because demographic changes over the next decades are not likely to be associated with reduced private saving, they constitute no argument for reducing the budget deficit. There remains the question of efficiency in tax collection. Maintaining current service levels for the elderly will require an increase in government spending from about 32 percent to 37 percent of GNP. Since the deadweight loss from taxation rises with the square of the tax rate, financing these expenditures on a pay-as-you-go basis will involve higher deadweight losses than maintaining a constant tax rate. We find, however, that these effects are likely to be small, amounting to at most several tenths of a percent of annual GNP.

We conclude by discussing the implications of our results for social security, for intergenerational redistribution more generally, and for population and immigration policy. Our findings suggest that population aging does not constitute a strong argument for accumulating a large social security trust fund, although if national saving is deemed to be inadequate for other reasons, the trust fund may be a convenient way to increase it.

\section{The Burden of Increased Dependency}

The economic consequences of population aging depend on the nature of the underlying demographic change as well as the relationship between the resource needs of individuals at different ages and their capacity for self-support. This section presents our estimates of the economic burden of increased dependency, noting the uncertainties associated with each step in the calculation.

\section{Changing Demographic Structure}

Figure 1 plots the Social Security Administration's projections of the elderly dependency ratio, the number of people aged 65 and over as a fraction of the population aged 20-64, and the total dependency ratio, 
Figure 1. Actual and Projected Dependency Ratios, United States, 1960-2065 ${ }^{\text {a }}$

Ratio

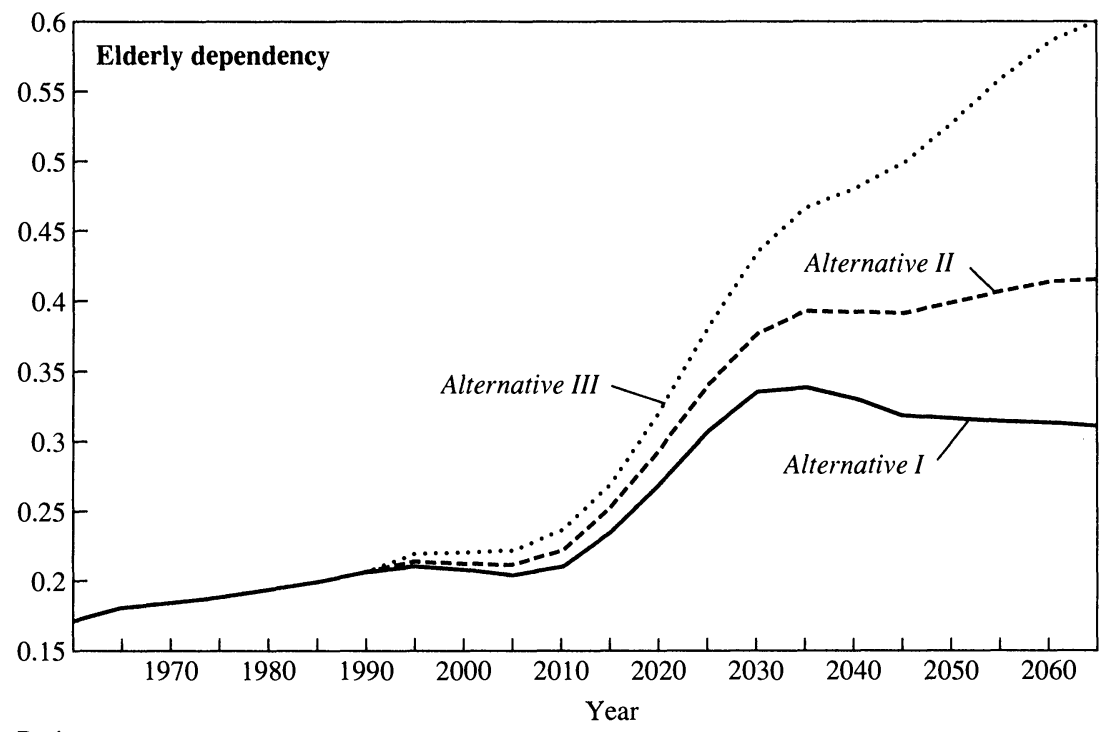

Ratio

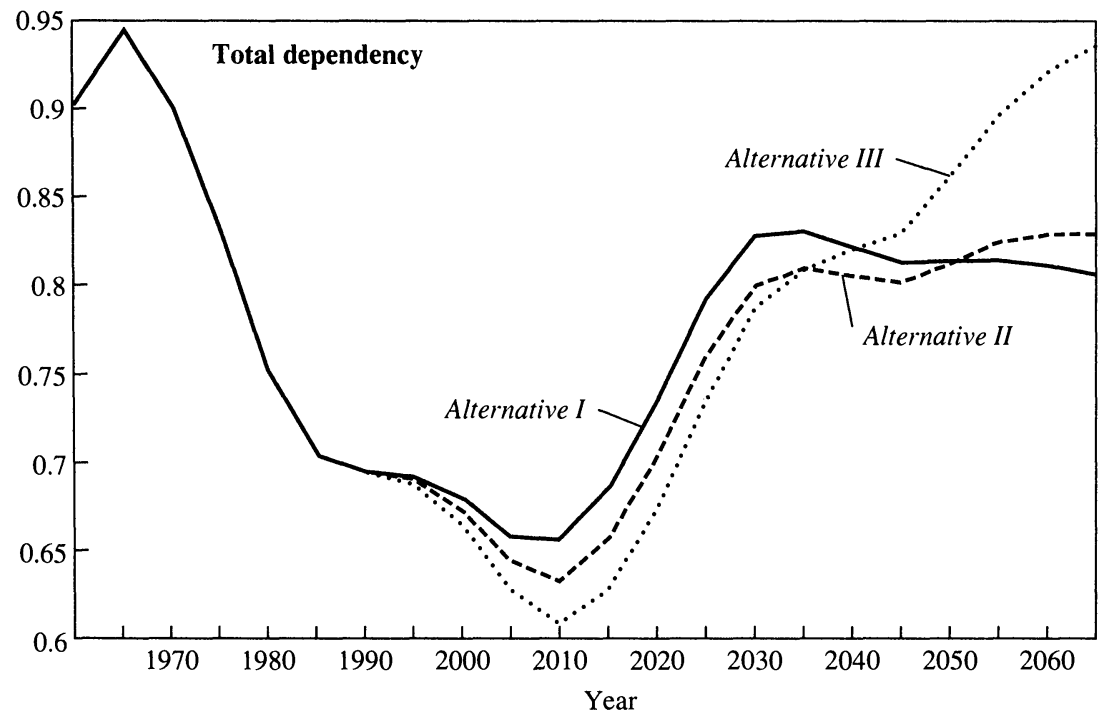

Sources: Board of Trustees of the Federal Old-Age and Survivors Insurance and the Disability Insurance Trust Funds (1988, table A1, p. 93) and unpublished data from the Social Security Administration underlying the published projections.

a. Elderly dependency ratio is the population aged 65 and over divided by the population aged 20-64. Total dependency ratio is population aged 65 and over plus the population under 20 divided by the population aged 20-64. 
the number of children plus elderly as a fraction of the working-age population, between 1960 and 2065. The figure shows the Social Security Administration's intermediate projections (alternative II) as well as outlying projections making more extreme assumptions about fertility and mortality changes. The projections agree in suggesting that the fraction of the population 65 and over will increase, and the fraction of the population under 20 will decrease, over the next 50 years. There is very little change, however, over the next decade.

Declining fertility is the principal source of the changing demographic patterns. ${ }^{1}$ In stable or declining populations, young cohorts account for a smaller share of the total population than they do in rapidly growing populations. In the years following World War II, the total fertility rate in the United States rose from 2.4 in 1945 to a peak of 3.7 in 1957. Fertility declined sharply during the late 1960s and early 1970s, falling to 1.7-well below replacement levels-by 1976. Since then, fertility has increased slightly, averaging 1.8 in the mid-1980s. Preliminary data for 1989 suggest continued increase, to 2.0. These changes have important implications for the demographic structure of the population over the next half-century.

The demographic effects of falling fertility have been reinforced by improvements in old-age mortality. In 1960, life expectancy for a 65year-old man was 12.9 years, compared with 15.0 years in 1990 . The mortality improvement for women has been even more pronounced, with life expectancy at age 65 increasing from 15.9 to 18.9 years during the past three decades. Current projections call for further improvements in life expectancies at age 65 , to 18.0 years for men, and 22.1 years for women, in $2060 .^{2}$

Long-term demographic projections like those in figure 1 are uncertain for several reasons. First, fertility forecasts are subject to large standard errors and are notoriously inaccurate, as is illustrated by figure 2 , which displays historical total fertility rates and the various Social Security Administration projections for the next half-century. The range of historical experience dwarfs the range between the Social Security

1. The relative importance of fertility declines, mortality improvement, and international migration is discussed in OECD (1988).

2. These data are drawn from Board of Trustees of the Federal Old-Age and Survivors Insurance and the Federal Disability Insurance Trust Funds (1990, table 11). More detailed information on mortality improvements can be found in Poterba and Summers (1987). 
Figure 2. Actual and Alternative Projected Total Fertility Rates, 1920-2080

Total fertility rate

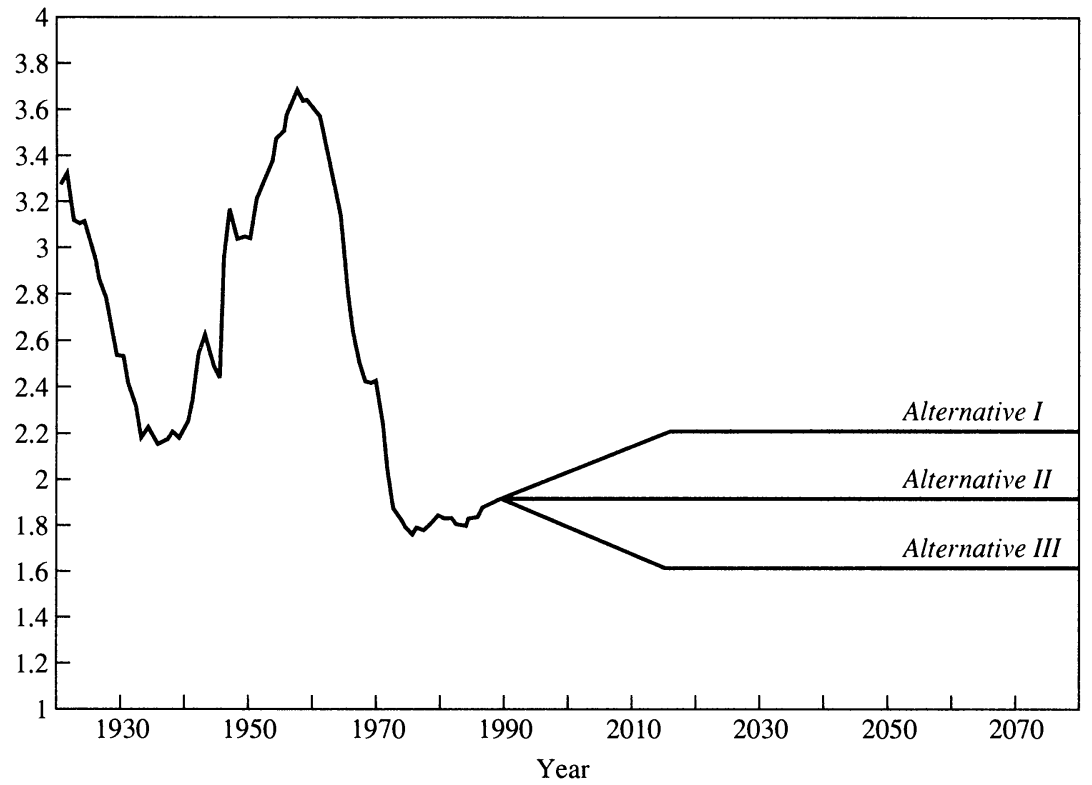

Source: Projected data are from Board of Trustees of the Federal Old-Age and Survivors Insurance and Disability Insurance Trust Funds (1988, table 11, p. 37). Historical data are from Social Security Area Population Projections. 1989 (1989, pp. 3-4).

Administration's optimistic and pessimistic projections. Even the factor of two difference between the predicted share of the population 65 or over in 2050 in the optimistic and pessimistic projections shown in figure 1 probably understates the true degree of demographic uncertainty. ${ }^{3}$ Postwar fertility projections in the United States anticipated neither the beginning, nor the end, of the baby boom.

A second important source of demographic uncertainty is the future course of immigration. The Social Security Administration's intermediate forecasts assume net immigration of 600,000 people a year until 2065-roughly the annual level of net legal and illegal immigration in the late 1980s. Assuming a constant immigrant flow for the next 75 years ignores potential changes in either immigration policy or the level of

3. The pessimistic case assumes an ultimate fertility rate of 1.6 , high for example in contrast to West Germany's current rate of 1.3. On the other hand, figure 2 may be deceptive, in that uncertainty regarding the average fertility rate over a 75 -year period may be much less than the uncertainty regarding fertility rates at any point in time. 
illegal migration. The age structure of the population is sensitive to the level of immigration because immigrants on average are younger than nonimmigrants. George Borjas reports that only 3.1 percent of those who immigrated to the United States between 1975 and 1979 were 65 or over in 1980, compared with 10.6 percent of the nonimmigrant population. ${ }^{4}$ Higher immigration during the next half-century would reduce dependency burdens.

Uncertainty about future mortality gains is a third, but less important, source of randomness in demographic projections. Most of the forecast rise in the number of Americans aged 65 or over is the result of large birth cohorts in the 1950s and 1960s. Even doubling the projected gains in life expectancy at age 65 between 1990 and 2060 would increase the number of elderly in 2060 by less than 20 percent, and change the ratio of the elderly to the working-age population by less than 8 percentage points.

Although there is much uncertainty regarding the future age composition of the U.S. population, the broad trend toward a rising average age, a greater number of dependent elderly, and fewer dependent children is indisputable. Moreover, uncertainty about long-term demographic change should not cloud the relatively certain short-term demographic outlook. Labor force growth in the next two decades, for example, is largely forecastable given the fertility experience of the past two decades. Along many dimensions, the near-term effects of demographic change operate in different directions from the long-term changes. To illustrate this we now explore alternative ways to calibrate the shifting burden of demographic change.

\section{The Support Ratio}

Demographic shifts affect the economy's consumption opportunities because they change the relative sizes of the self-supporting and dependent populations. We summarize these changes in the support ratio, denoted $\alpha$, which we define as the effective labor force, $L F$, divided by the effective number of consumers, $C O N$ :

$$
\alpha=L F / C O N \text {. }
$$

The share of the population aged 65 and over is one, but not the only, determinant of this ratio. The support ratio is also influenced by the

4. Borjas (1990, pp. 41, 46). 
relative consumption needs of people of different ages, as well as by changes in the retirement age, labor force participation rates, and the earning power of those who are working. Because there are several approaches to measuring and projecting each of these factors, we present several different measures of the support ratio.

The first issue in measuring the support ratio concerns the relative consumption needs of people at different ages. One assumption, which we label CON1, defines effective consumption as if all people have identical resource needs:

$$
\text { CON1 }=\sum_{i=1}^{99} N_{i}
$$

where $N_{i}$ is the number of people of age $i$. This measure of needs is implicit in the commonly cited total dependency ratio shown in figure 1.

An alternative approach involves differentiating the resource needs of people at different ages. We develop this approach in a second measure of effective consumption needs, $C O N 2$, which has three parts: private nonmedical expenses, public education expenses, and medical care. For private nonmedical outlays, we follow Edward Lazear and Robert Michael in assuming that all people 20 and older have identical needs, while those under 20 (18 in their work) have needs equal to onehalf those of adults. ${ }^{5}$ For public education expenses, we assume per capita outlays of $\$ 2,553$ (1989 dollars) per person under $20, \$ 309$ per person aged 20-64, and $\$ 84$ per person aged 65 and over. These estimates are explained in more detail below. For medical care, we assume that needs are proportional to total spending by age: $\$ 1,262$ per person per year for those under 64 and $\$ 5,360$ for those 65 and over. ${ }^{6}$ Adding together

5. Lazear and Michael (1980, p. 102) estimate that a child raises equivalent scale consumption for a husband-wife family by 22.2 percent, or by 44.4 percent as much as the average consumption of either parent. There is some evidence that nonmedical consumption needs of the elderly may be lower than those for younger people. For example, the U.S. Department of Agriculture poverty line assumes that food expenditures by the elderly are 90 percent of those for prime-aged individuals. The ongoing trend toward more elderly living in single households, however, suggests that the relative expenditure needs of the elderly may rise in the future.

6. These relative medical costs are based on the current age structure of the elderly population. As the average age of those 65 or over rises, the relative cost of medical care for the elderly will increase. In 1987 total annual per capita health expenditures for people aged 65-69 were $\$ 3,728$, compared with $\$ 9,178$ for those aged 85 and over. Holding agespecific expenditure patterns constant at their 1987 level, average spending per person aged 65 and over would be approximately 10 percent higher with the age composition expected in 2060 rather than that in 1990 . See Waldo and others (1989). 
these three components, we construct a needs-weighted consumption measure, $C O N 2$, as 0.72 times the number of people under 20, plus the number aged 20-64, plus 1.27 times the number 65 and over. ${ }^{7}$

The relative needs of elderly and nonelderly consumers can be affected by demographic factors such as mortality improvements. Edward Schneider and Jack Guralnik observe that only 3 percent of men and 6 percent of women 65 and over reside in nursing homes, while 15 percent of men and 25 percent of women 85 and over are in such homes. The high cost of nursing home care $(\$ 23,600$ per resident per year in 1985$)$ makes it an important contributor to the total cost of caring for the aged population. ${ }^{8}$

The appropriate weighting of young and old dependents may depend on more than their consumption demands. Many of the transfers to children take place within the family, while those to elderly dependents are largely mediated by the government. A Scandinavian proverb, brought to our attention by George Akerlof, suggests that "one mother can care for ten children, but ten children cannot care for one mother." Individuals may derive more pleasure from caring for children than from caring for elderly dependents, making the burdens of an increasingly elderly population more onerous than the burdens of caring for a young population. ${ }^{9}$

We also consider two different measures of the effective labor force. The first, $L F 1$, assumes that all people aged 20-64 are in the labor force, while individuals 19 and under or 65 and over are not:

$$
L F 1=\sum_{i=20}^{64} N_{i}
$$

Our second measure, $L F 2$, recognizes that both human capital and labor force participation rates vary by age. We use data on the average 1989 earnings $(w)$ of people of each age (measured in five-year intervals),

7. The needs-weighted consumption measure, $C O N 2$, is defined as

$$
\operatorname{CON} 2=\sum_{i=1}^{99} S_{i} N_{i}
$$

where $S_{i}$ is the respective weight for an individual at age $i$.

8. Schneider and Guralnik (1990).

9. Provided the "warm glow" of caregiving does not affect the marginal utility of consuming goods, it should not affect our needs weighting of different-aged households. It will affect the total utility of households. 
along with Social Security Administration forecasts of age-specific labor force participation rates, $P R$, to estimate $L F 2:^{10}$

$$
L F 2=\sum_{i=15}^{80} w_{i} P R_{i} N_{i}
$$

This recognizes that the earning capacity of a society with a high fraction of people in middle age is higher than that of a society with many new entrants to the labor force. ${ }^{11}$

\section{Support Ratio Projections, 1990-2060}

Because the level of the support ratio is less informative than its changes from year to year, we focus on $\hat{\alpha}_{t}$, the percentage change in the support ratio between 1990 and year $t$ :

$$
\hat{\alpha}_{t}=\left(L F_{t} / C O N_{t}\right) /\left(L F_{1990} / C O N_{1990}\right)-1 .
$$

We report support ratios corresponding to each combination of effective labor force and effective consumption measures.

Table 1 shows the historical and projected changes in $L F$ and $C O N$ and demonstrates that regardless of measurement method, growth in both the labor force and consumption requirements declines during the next half-century. For example, the earnings-weighted labor force grew at a 1.7 percent annual rate during the 1980s, but will shrink in four of the five decades between 2010 and 2060. In the nearer term, labor force growth also slows. By the first decade of the next century, labor force growth is only one-fourth its rate during the 1970s. Total needs-weighted consumption, which grew at a 1.1 percent annual rate during the $1980 \mathrm{~s}$, rises by less than one tenth of 1 percent a year between 2040 and 2060 .

Table 2 and figure 3 show the percentage change in the four alternative measures of the support ratio. Four conclusions stand out. First, because both our measures of the labor force grow more slowly than population

10. These data are from the Bureau of Labor Statistics, Usual Weekly Earnings of Full-Time Wage and Salary Workers and Usual Weekly Earnings of Employed \& PartTime Wage and Salary Workers. We adjust part-time workers to full-time equivalent employees.

11. This labor force concept includes only market activity, neglecting the value of labor devoted to household production. It may therefore overstate the historical changes in the effective labor force that were partly due to rising market labor force participation by women. 
Table 1. Actual and Projected Average Annual Growth in Labor Force and Consumption, United States, 1950-2060

Percent

\begin{tabular}{cccccc}
\hline & \multicolumn{2}{c}{ Labor force } & & \multicolumn{2}{c}{ Consumption } \\
\cline { 2 - 3 } & $\begin{array}{c}\text { Population } \\
20-64\end{array}$ & $\begin{array}{c}\text { Earnings- } \\
\text { weighted } \\
\text { population } \\
\text { Period }\end{array}$ & & $\begin{array}{c}\text { Unweighted } \\
\text { (LF })\end{array}$ & $\begin{array}{c}\text { Needs- } \\
\text { weighted } \\
\text { (CON2) }\end{array}$ \\
\hline $1950-1960$ & 0.74 & 1.18 & 1.77 & 1.66 \\
$1960-1970$ & 1.25 & 1.19 & 1.23 & 1.28 \\
$1970-1980$ & 1.73 & 2.05 & 0.91 & 1.13 \\
$1980-1990$ & 1.29 & 1.69 & 0.95 & 1.08 \\
$1990-2000$ & 0.83 & 1.07 & 0.70 & 0.75 \\
$2000-2010$ & 0.80 & 0.48 & 0.57 & 0.65 \\
$2010-2020$ & 0.06 & -0.03 & 0.48 & 0.60 \\
$2020-2030$ & -0.26 & -0.10 & 0.29 & 0.42 \\
$2030-2040$ & 0.11 & 0.07 & 0.14 & 0.17 \\
$2040-2050$ & 0.00 & -0.03 & 0.04 & 0.05 \\
$2050-2060$ & -0.06 & -0.02 & 0.03 & 0.05 \\
\hline
\end{tabular}

Source: Board of Trustees of the Federal Old-Age and Survivors Insurance and Disability Insurance Trust Funds (1988). Projected data for 1990-2060 use alternative IIb. Data show geometric average annual changes in labor force and consumption needs under IIb.

during the next 70 years, there is a long-run decline in the support ratio. The size of the decline is more sensitive to our assumptions about consumption than to our measure of the effective labor force. ${ }^{12}$ When consumption needs are assumed to be equal for people of all ages, the support ratio for $L F 1$ ( $L F 2$ ) declines by 7.4 percent ( 7.8 percent) between 1990 and 2060. When we adjust consumption using our needs-weighted measure, the decline in the support ratio is more pronounced: 11.5 percent and 11.8 percent for $L F 1$ and $L F 2$, respectively.

It is difficult to know whether these estimates represent a large or a small burden spread over 70 years. They correspond to between a 0.10 percent and 0.15 percent reduction in the annual productivity growth rate, which is small relative to the uncertainty in secular productivity growth. They represent three to four times as large a cost as the peace dividend that the United States is likely to enjoy over the next decade.

12. For the period $1950-90$, the support ratios are sensitive to our choice of labor force concept, primarily because of significant changes in labor force participation rates, most notably among women. 
Table 2. Changes in Support Ratio Relative to 1990, United States, 1950-2060

Percent

\begin{tabular}{ccccc}
\hline & $\begin{array}{c}\text { Unweighted } \\
\text { population } \\
\text { aged 20-64) } \\
\text { unweighted } \\
\text { consumption }\end{array}$ & $\begin{array}{c}\text { Earnings- } \\
\text { weighted } \\
\text { population/ } \\
\text { unweighted } \\
\text { consumption } \\
\text { (LF1/CON1) }\end{array}$ & $\begin{array}{c}\text { Unweighted } \\
\text { population } \\
\text { aged 20-64) } \\
\text { needs- } \\
\text { weighted } \\
\text { consumption } \\
\text { (LF1/CON2) }\end{array}$ & $\begin{array}{c}\text { Earnings- } \\
\text { weighted } \\
\text { population/ } \\
\text { needs- } \\
\text { weighted } \\
\text { consumption } \\
(\text { LF2/CON2) }\end{array}$ \\
\hline 1950 & -1.4 & -11.5 & 1.4 & -9.0 \\
1960 & -10.9 & -16.5 & -7.4 & -13.2 \\
1970 & -10.8 & -16.9 & -7.7 & -14.0 \\
1980 & -3.3 & -7.0 & -2.0 & -5.8 \\
1990 & 0.0 & 0.0 & 0.0 & 0.0 \\
2000 & 1.3 & 3.7 & 0.8 & 3.2 \\
2010 & 3.8 & 2.8 & 2.3 & 1.4 \\
2020 & -0.5 & -2.3 & -3.1 & -4.8 \\
2030 & -5.9 & -6.0 & -9.5 & -9.6 \\
2040 & -6.2 & -6.6 & -10.0 & -10.5 \\
2050 & -6.5 & -7.3 & -10.4 & -11.2 \\
2060 & -7.4 & -7.8 & -11.5 & -11.8 \\
\hline
\end{tabular}

Source: Same as table 1. The earnings-weighted labor force measure uses contemporaneous and projected labor force participation rates and the 1987 age-earnings profiles for men and women to form effective labor forces.

In yet another metric, a three- to four-year increase in the average age at retirement, or a 19 percentage point increase in female labor force participation, would be needed to offset the increase in dependency.

Second, in the next two decades there is a decline in economic dependency (a rise in the support ratio) because the declining number of dependent children more than offsets the rising number of dependent elderly. Between 1990 and 2010, when the baby boom generation is part of the labor force and relatively small birth cohorts are retiring, the labor force grows more rapidly than the dependent population. This leads to an improvement in the support ratio by $2010 .{ }^{13}$

Figure 4 provides further detail on the differential burdens of young and aged dependents. It plots the contributions of both children and the elderly to the support ratio defined using $L F 2$ and $C O N 2$. In this case

13. Measures that define effective consumption with less weight on children show smaller gains in the support ratio during the next two decades. If the consumption weight based on needs is set equal to zero for children, the support ratio actually declines by between 1 percent and 2 percent during 1990-2010. 
Figure 3. Actual and Projected Changes in Support Ratio (Relative to 1990), Four Alternative Measures, United States, 1960-2065

Ratio

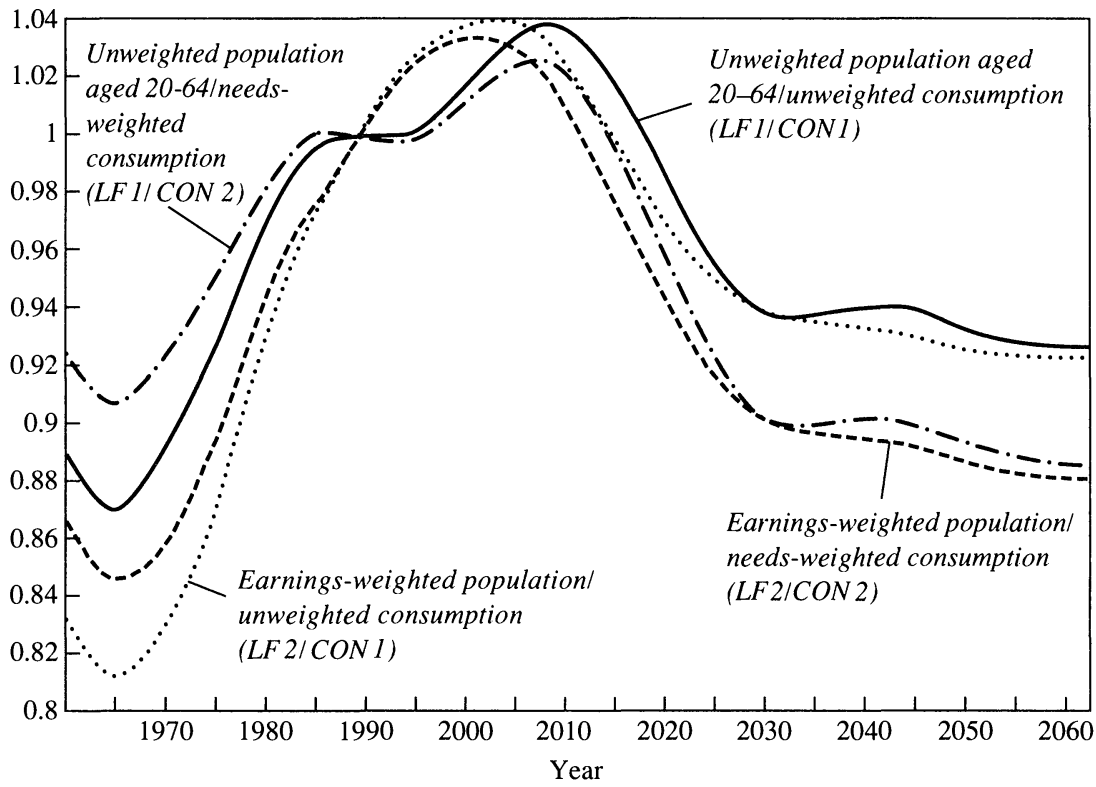

Source: Table 2.

$\alpha=P /(C+P+E)$, where $P$ is the number of prime-aged adults, $C$ the number of effective children, and $E$ the number of effective elderly. Then the percentage change in the support ratio can be written in terms of the percentage change in its components:

$$
\hat{\alpha}=(\hat{P}-\hat{C})[C /(C+P+E)]+(\hat{P}-\hat{E})[E /(C+P+E)] .
$$

The first term is due to differential growth rates of the prime-aged and dependent children populations, the second to the differential growth between the prime-aged and elderly groups. Figure 4 plots these two terms, showing that virtually all the improvement in the support ratio in the near term is from a shrinking share of children in the population. Most of the long-run decline is a result of rising numbers of elderly during 2010-2035.

Third, the changes in the support ratio between 1990 and 2060 are usually no larger than, and in some cases significantly smaller than, 
Figure 4. Contributions of Young and Elderly Dependents to Percentage Changes in the Support Ratio (Relative to 1990), 1955-2065

Change in consumption relative to 1990 (percent)

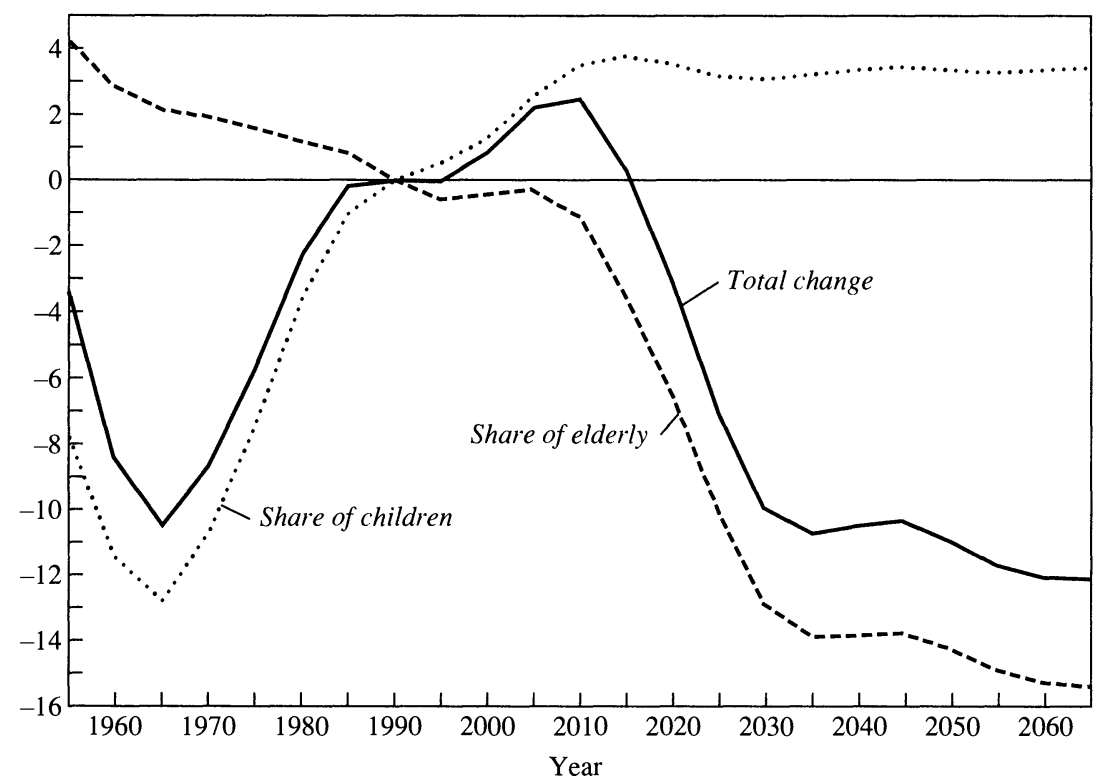

Source: Authors' calculations using equation 6. The earnings-weighted labor force measure ( $L F 2)$ and the needsweighted consumption measure (CON2) are used. See text for details.

those between 1960 and 1990. With our preferred measures, $L F 2$ and CON2, the support ratio was 14.0 percent lower in 1970 than 1990. By 2060, it is projected once again to be below the 1990 level, this time by 11.8 percent. Our support ratio peaks around 2010. One reason why the slow growth of real wages in the U.S. economy since 1973 has been less burdensome than it might have otherwise been is that the labor force participation rate has risen. The figures show clearly that the gains in sustainable consumption from demographic developments are now nearly exhausted.

Finally, while the decline in the support ratio by the middle of the next century is large, there is still substantial uncertainty about the ultimate burden. Figure 5 presents support ratios using $L F 2$ and $C O N 2$ under the three Social Security Administration demographic forecasts. There are substantial differences in the scenarios, particularly between the more pessimistic alternative III and alternative II, which is our 
Figure 5. Percentage Change in Support Ratio (Relative to 1990), Alternative Demographic Assumptions, 1950-2065

Index relative to 1990

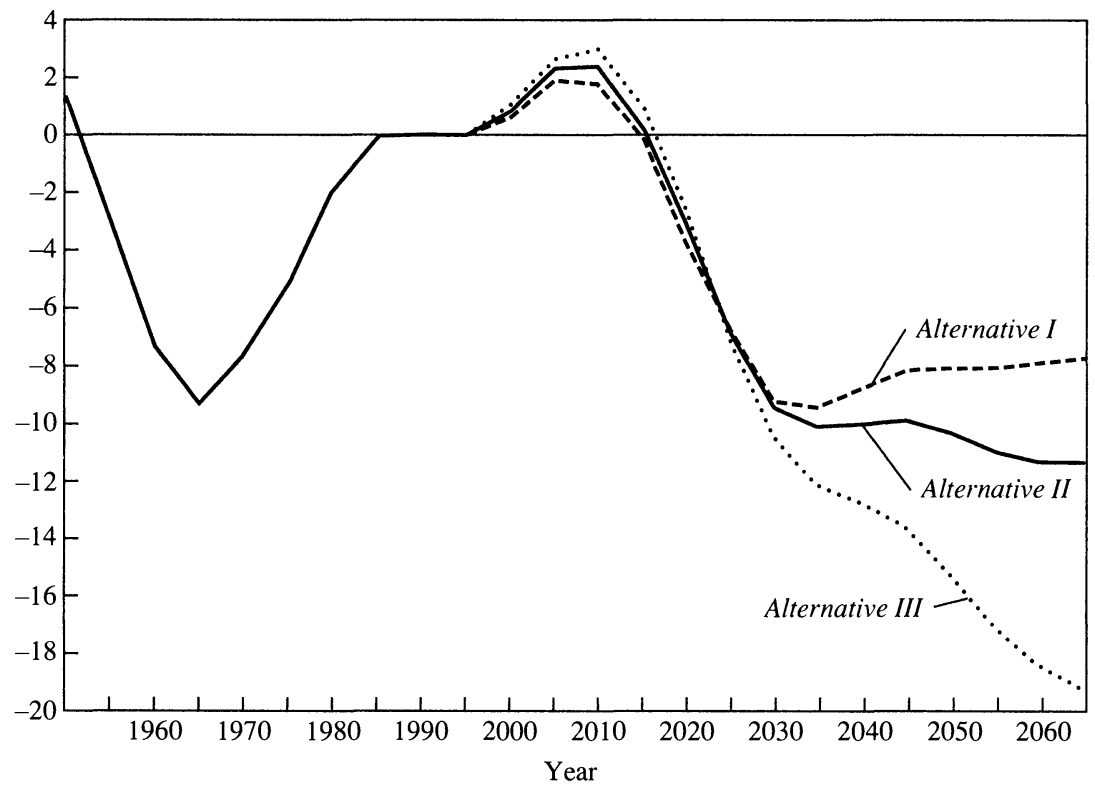

Source: Authors' calculations using Board of Trustees of the Federal Old-Age and Survivors Insurance and Disability Insurance Trust Funds (1988) and the needs-weighted consumption (CON2) and earnings-weighted labor force $(L F 2)$ measures.

standard case. The decline in the support ratio is almost twice as large in the pessimistic scenario as in our benchmark. Even in the optimistic alternative I, the support ratio still declines by almost 8 percent between 1990 and 2060.

\section{Capital Accumulation and Shifting Dependency Burdens}

This section explores how the demographic shifts described above affect the economy's sustainable level of consumption, and how society should plan for these changes. We find that sustainable consumption increases for the next several decades and that an economy with otherwise optimal national saving would reduce its saving in response to the coming demographic changes. 


\section{Steady-State Consumption Opportunities}

Demographic change has two effects on consumption opportunities. First, an increase in dependency lowers output per person, thus reducing consumption per capita. Second, slower labor force growth reduces investment requirements, thus reducing the need for saving and increasing consumption per capita.

To examine the importance of these two changes for consumption opportunities, we assume that output per worker, $f(k)$, where $k$ is the capital-labor ratio, is divided between consumption and investment. Maintaining constant capital intensity requires investment of $n k$, where $n$ is the labor force growth rate. ${ }^{14}$ For expositional ease, we have assumed away depreciation and technical change. ${ }^{15}$ When the labor force and the population are not the same, consumption per capita is only a fraction of output net of investment per worker. This fraction is the ratio of the number of workers to the size of the population, precisely the support ratio $(\alpha)$ defined above. The resulting equation for per capita consumption is:

$$
c=\alpha[f(k)-n k] .
$$

This expression can be rewritten to find the change in steady-state consumption for changes in $\alpha$ and $n$ :

$$
\Delta c / c=\Delta \alpha / \alpha-[\alpha(k / c) \Delta n+\Delta \alpha(k / c) \Delta n],
$$

with $c, k$, and $\alpha$ evaluated at the initial steady state. ${ }^{16}$ Equation 8 illustrates the two steady-state effects of demographic change. A decline in the labor force-population ratio $(\alpha)$ reduces the level of per capita consumption that is feasible given the economy's capital stock. At the same time, a decline in the growth rate of the labor force $(n)$ permits more consumption for a given capital-output ratio. Society receives a "consumption dividend" when it is able to invest less and still maintain

14. A substantial part of the U.S. capital stock is residential capital. The natural steadystate condition for housing requires investment at the rate of population growth, not the rate of labor force growth. In steady state, these two growth rates will coincide.

15. We incorporate both in our numerical simulations below.

16. We have arbitrarily assigned the second-order term to the second effect in our decomposition. We have also assumed that the capital-labor ratio, and thus the capitalconsumption ratio, do not change with demographic change. The model we present below justifies this assumption. 
Table 3. Shifting Steady-State Per Capita Consumption from Demographic Shocks, 1960-2065 ${ }^{\text {a }}$

Percent

\begin{tabular}{|c|c|c|c|c|c|c|}
\hline \multirow[b]{2}{*}{ Year } & \multicolumn{3}{|c|}{ Unweighted consumption (CON1) } & \multicolumn{3}{|c|}{ Needs-weighted consumption (CON2) } \\
\hline & $\begin{array}{c}\text { Effect of } \\
\text { dependency }\end{array}$ & $\begin{array}{l}\text { Effect of } \\
\text { labor force } \\
\text { growth }\end{array}$ & $\begin{array}{l}\text { Total } \\
\text { change in } \\
\text { per capita } \\
\text { consump- } \\
\quad \text { tion }\end{array}$ & $\begin{array}{c}\text { Effect of } \\
\text { dependency }\end{array}$ & $\begin{array}{l}\text { Effect of } \\
\text { labor force } \\
\text { growth }\end{array}$ & $\begin{array}{l}\text { Total } \\
\text { change in } \\
\text { per capita } \\
\text { consump- } \\
\quad \text { tion }\end{array}$ \\
\hline & \multicolumn{6}{|c|}{ Population 20-64 as effective labor force (LF1) } \\
\hline 1960 & -10.9 & 0.4 & -10.6 & -7.4 & 0.4 & -7.1 \\
\hline 1970 & -10.8 & -1.8 & -12.6 & -7.7 & -1.8 & -9.5 \\
\hline 1980 & -3.3 & -2.4 & -5.7 & -2.0 & -2.4 & -4.5 \\
\hline 1990 & 0.0 & 0.0 & 0.0 & 0.0 & 0.0 & 0.0 \\
\hline 2000 & 1.3 & 0.0 & 1.3 & 0.8 & 0.0 & 0.8 \\
\hline 2010 & 3.8 & 1.0 & 4.8 & 2.3 & 1.0 & 3.4 \\
\hline 2020 & -0.5 & 3.0 & 2.5 & -3.1 & 2.9 & -0.2 \\
\hline 2030 & -5.9 & 2.5 & -3.4 & -9.5 & 2.4 & -7.1 \\
\hline 2040 & -6.2 & 1.8 & -4.3 & -10.0 & 1.8 & -8.3 \\
\hline 2050 & -6.5 & 2.5 & -4.0 & -10.4 & 2.4 & -8.0 \\
\hline 2060 & -7.4 & 2.1 & -5.3 & -11.5 & 2.0 & -9.4 \\
\hline \multirow[t]{2}{*}{2065} & -7.4 & 2.2 & -5.2 & -11.5 & 2.1 & -9.4 \\
\hline & \multicolumn{6}{|c|}{ Earnings-weighted labor force (LF2) } \\
\hline 1960 & -16.5 & 1.1 & -15.4 & -13.2 & 1.2 & -12.1 \\
\hline 1970 & -16.9 & -0.4 & -17.3 & -14.0 & -0.4 & -14.4 \\
\hline 1980 & -7.0 & -1.9 & -9.0 & -5.8 & -2.0 & -7.8 \\
\hline 1990 & 0.0 & 0.0 & 0.0 & 0.0 & 0.0 & 0.0 \\
\hline 2000 & 3.7 & 2.2 & 5.9 & 3.2 & 2.2 & 5.4 \\
\hline 2010 & 2.8 & 3.5 & 6.3 & 1.4 & 3.5 & 4.9 \\
\hline 2020 & -2.3 & 4.4 & 2.1 & -4.8 & 4.2 & -0.6 \\
\hline 2030 & -6.0 & 3.7 & -2.3 & -9.6 & 3.6 & -6.0 \\
\hline 2040 & -6.6 & 3.6 & -3.0 & -10.5 & 3.5 & -7.0 \\
\hline 2050 & -7.3 & 3.9 & -3.5 & -11.2 & 3.7 & -7.5 \\
\hline 2060 & -7.8 & 3.6 & -4.1 & -11.8 & 3.5 & -8.3 \\
\hline 2065 & -7.8 & 3.7 & -4.2 & -12.0 & 3.5 & -8.4 \\
\hline
\end{tabular}

Source: Authors' calculations.

a. The table shows the steady-state change in consumption relative to the 1990 base if demographic change were to reach a steady state at the level of the indicated year.

a given level of per capita output. This "Solow effect" offsets the longrun dependency effect on per capita consumption.

Table 3 reports the size of these two effects. For each year, we show the steady-state consumption change associated with changes in $\alpha$ (first column), $n$ (second column), and the combined effect (third column). The consumption changes due to the dependency increase are the same 
as the changes in the support ratio shown in table 2; the other columns show the extent to which changing investment needs offset this effect.

Two results emerge from table 3 . First, the consumption benefits from reduced investment requirements are substantial. During the next two decades, the benefits of slower labor force growth will be about a 1 percent to 3.5 percent increase in per capita consumption, using the 1990 base. Since the labor force was growing more rapidly in the 1970s and 1980 s than in 1990, the effect of reduced investment requirements is even larger relative to earlier years. By the middle of the next century, the benefits of slower labor force growth will be between 2.1 percent and 3.7 percent of per capita consumption. This is between one-quarter and one-half of the adverse dependency effects of the changing population mix.

Second, while the investment effect offsets a substantial part of the long-term dependency increase, it magnifies the short-run effect of rising support ratios. Reduced dependency and slowing labor force growth both increase consumption possibilities so that by 2010 , society will be between 3.4 percent and 6.3 percent richer, depending on the combination of labor force and needs measures. Only after 2020 does the increase in dependency outweigh the decline in investment needs and reduce consumption below its 1990 level.

The steady-state consumption decline between 1990 and 2060 is estimated at between 4.2 percent (with effective consumers set equal to total population and the earnings-weighted labor force) and 9.4 percent (with effective consumers computed using our needs-weighted measure and the unweighted labor force). As with the support ratios, this finding is more sensitive to our definition of consumption needs than to our definition of the effective labor force. For almost all cases, however, society is richer in the new steady state than in 1970 or 1980.

\section{Demographic Change and Optimal Capital Accumulation}

The results presented so far suggest that in the short run, demographic changes will raise the level of consumption that can be sustained while maintaining the level of capital intensity. In the long run, they will reduce the sustainable level of consumption. The question then becomes how society should adjust its saving policy to these developments. To study this question, we use the standard Ramsey optimal growth model. 
We assume that a social planner seeks to maximize

$$
V=\int_{0}^{\infty} e^{-\rho t} P_{t} U\left(c_{t}\right) d t
$$

where $P_{t}$ denotes the number of individuals alive in period $t, c_{t}$ is per capita consumption in period $t$, and $\rho$ is the social time preference rate. We denote the current period as time zero. This social welfare function weights the utility, denoted as $U$, of a representative individual in each generation by the generation's size. ${ }^{17}$ Using our earlier notation, $P_{t}=$ $N_{t} / \alpha_{t}$, where $N_{t}$ is the labor force in period $t$ and $\alpha_{t}$ is the support ratio.

Our analysis abstracts from the overlapping generations structure of the actual population. Calvo and Obstfeld formally justify this procedure by demonstrating that if age-specific transfer programs like social security are available, and if individual utility functions are additively separable, then "the Cass-Koopmans-Ramsey framework can be used to evaluate paths of aggregate consumption even in models where different generations co-exist. ... the planning problem facing the government can be decomposed into two subproblems, a standard problem of optimal aggregate capital accumulation and a problem of distributing consumption optimally on each date among the generations alive then." 18 The social planner maximizes equation 9 subject to a capital accumulation constraint analogous to equation $7: 19$

$$
\dot{k}_{t}=f\left(k_{t}\right)-c_{t} / \alpha_{t}-n_{t} k_{t} .
$$

If $\alpha_{t}=1$, equation 10 reduces to the standard resource constraint in neoclassical growth models. The consumption profile that solves this problem satisfies:

$$
\dot{c}_{t} / c_{t}=\sigma\left[f^{\prime}\left(k_{t}\right)-\rho\right],
$$

where $\sigma=\left[-U^{\prime}\left(c_{t}\right) / c_{t}\right]\left[U^{\prime \prime}\left(c_{t}\right)\right]$, the elasticity of substitution in consumption.

17. Some might argue for using an alternative objective function that does not weight the average utility of different generations by the number of people in the generation. This will lead the social planner to raise average consumption in small cohorts relative to that in larger cohorts, because the aggregate resource cost of raising the average consumption of people in small cohorts is less than that for large cohorts. We see no compelling ethical argument for weighting people in different sized cohorts differently.

18. Calvo and Obstfeld (1988, p. 163).

19. The optimal plan must also satisfy transversality conditions noted for example by Blanchard and Fischer (1989). 
Figure 6. Steady-State Consumption Response to an Increase in Dependency (Decline in $\alpha$ )



In steady state with no technical progress, per capita consumption and the capital-labor ratio must be constant. From the Euler equation 11 , we find that constant consumption requires

$$
k^{*}=f^{\prime-1}(\rho) .
$$

This locus, a vertical line in $(c, k)$ space, is drawn in figure 6 . Constancy of the capital-labor ratio given in equation 7 yields the second locus depicted in figure 6 as the solid line $\dot{k}=0$.

Permanent reductions in $\alpha$, the support ratio, scale back the feasible level of per capita consumption for each $k$, shifting the $\dot{k}=0$ locus as shown by the dashed line in figure 6 . The steady-state capital-labor ratio is unaffected by this change, so the only effect of this shock is an immediate and permanent decline in consumption per capita. Reductions in $n$, the labor force growth rate, would have the opposite effect, shifting the $\dot{k}=\mathbf{0}$ frontier out. The steady-state consumption effect of a demographic shift such as a fertility decline, which reduces both $\alpha$ and $n$, depends on which of these effects may be larger. Reductions in $n$ would 
unambiguously reduce the optimal steady-state saving rate while increases in $\alpha$ would have no effect on steady-state savings. ${ }^{20}$

The actual demographic projections for the United States are more complex than an immediate shift in either $\alpha$ or $n$, however. For the next several decades, the net effect of demographic change is an outward shift in the $k=0$ locus, followed by a period of inward shift that terminates with the locus below its current level. When consumers have perfect foresight and recognize the complex nature of the demographic transition, the initial consumption response to news of the demographic transition is theoretically ambiguous.

This ambiguity suggests the need for explicit numerical simulations to address the optimal consumption response. We assume that the utility function in equation 9 has the form

$$
U\left(c_{t}\right)=\left(c_{t}^{1-1 / \sigma}-1\right) /(1-1 / \sigma),
$$

where $\sigma$ is the elasticity of substitution in consumption. We also assume a constant elasticity of substitution production function:

$$
f\left(k_{t}\right)=\left[a k_{t}^{1 / 1-\beta}+b\right]^{1-\beta} .
$$

The elasticity of substitution in production is $\beta$. To find the transition path between one steady state and another, we discretize differential equations 10 and 11 and employ a grid-search algorithm to find the initial consumption level that will lead the economy to the new steady state. ${ }^{21}$

Our simulations also allow for labor-augmenting technical change $(g)$ and depreciation ( $\delta$ ), which are introduced into equations 10 and 11 in the standard way. ${ }^{22}$ Although consumption grows over time when there is technical progress, the consumption numbers we report are relative to the consumption that would have been possible without demographic change. We assume that technical change is equal to 1.4 percent a year, the Social Security Administration's steady-state projection. ${ }^{23}$ The depreciation rate is set equal to 4.1 percent, the U.S. average during 1952-

20. This is easily seen from the Harrod-Domar condition $k / f(k)=s / n$, where $s$ is the saving rate out of national income, and the observation that neither changes in $\alpha$ nor changes in $n$ affect optimal steady-state capital intensity in the Ramsey model.

21. Because the Social Security Administration forecasts population in every fifth year, we interpolate annual observations using a smooth interpolator. The results are not sensitive to the frequency of the data.

22. Following Blanchard and Fischer (1989), we express capital per "effective worker," where effective workers grow at $n+g$. Consumption is expressed per "effective person." In equation 11 , the discount factor becomes $(\rho+\delta+g / \sigma)$.

23. Our results are insensitive to the choice of $g$. 
$87 .{ }^{24}$ Finally, we use data for this period on payments to labor and capital to estimate capital's share in gross output-33.2 percent. Over this same period, the capital-output ratio averaged $2.3 .{ }^{25}$ These two numbers imply a steady-state marginal product of capital of 14.4 percent. From equation 11 , this implies an effective discount rate $(\rho+g / \sigma)$ of 10.3 percent: that is, the steady-state marginal product of capital less depreciation.

We present results using two values of $\sigma$, a benchmark case of unit elasticity $(\sigma=1)$ and an alternative elasticity of substitution of onetenth $(\sigma=0.1)$. We also choose two values for the elasticity of substitution in production, a benchmark of unit elasticity $(\beta=1)$ and an alternative elasticity of one-half $(\beta=0.5)$. When the elasticity of substitution in consumption is low, consumption today is not a good substitute for consumption tomorrow, and we expect more consumption smoothing. When the elasticity of substitution in production is low, saving does not get a high return since the extra capital does not substitute well for the smaller labor force, and we expect less consumption smoothing.

Demographic change has occurred gradually over the past 25 years, as the baby boom has given way to the baby bust. It is not obvious how best to model these changes as a single shock. Initially, we assume the economy is in steady state with values of $\alpha$ and $n$ corresponding to those prevailing in 1990, and ask how consumption and saving should evolve henceforth. Because some of the consequences of demographic change were already known by 1990 , we go on to examine how consumption and saving should have responded in 1970 and 1980 if news of demographic change had suddenly arrived.

For all our simulations, we use the trajectories of $\alpha$ and $n$ implied by the Social Security Administration's alternative IIb forecasts, and further assume that the predicted values for 2065 persist as the economy's final steady state. ${ }^{26}$ The resulting consumption changes are thus the

24. Our depreciation rate is estimated as capital consumption allowances divided by the aggregate capital stock. We define aggregate capital stock as national assets minus consumer durables minus one half of the value of land. Consumer durables are excluded since they are not included in output. One half of land is included in capital to allow for natural resource values to change.

25. Capital's share in output is total output less wages and salaries, two-thirds of proprietors' income (the estimated labor compensation), and indirect business taxes, divided by output less indirect business taxes.

26. Alternative IIb projections embody the alternative II forecasts regarding demographic change, as well as an intermediate set of economic forecasts. 
Table 4. Optimal Consumption Response to Demographic Shocks, United States, 1990-2060 ${ }^{\mathrm{a}}$

\begin{tabular}{|c|c|c|c|c|c|}
\hline \multirow[b]{2}{*}{ Item } & \multirow[b]{2}{*}{$\begin{array}{c}\text { Static } \\
\text { expectations }\end{array}$} & \multicolumn{4}{|c|}{ Perfect foresight with alternative elasticities ${ }^{\mathrm{b}}$} \\
\hline & & $\begin{array}{l}\beta=1 \\
\sigma=1\end{array}$ & $\begin{array}{c}\beta=1 \\
\sigma=0.1\end{array}$ & $\begin{array}{c}\beta=0.5 \\
\sigma=1\end{array}$ & $\begin{array}{l}\beta=0.5 \\
\sigma=0.1\end{array}$ \\
\hline \multicolumn{6}{|c|}{ Case 1. Labor force population 20-64 and unweighted consumption } \\
\hline Initial steady state & 100.0 & 100.0 & 100.0 & 100.0 & 100.0 \\
\hline Initial adjustment & 100.0 & 100.6 & 101.1 & 100.4 & 101.0 \\
\hline \multicolumn{6}{|l|}{ Time path } \\
\hline 2000 & 101.3 & 101.4 & 101.3 & 101.4 & 101.3 \\
\hline 2010 & 104.8 & 103.3 & 101.7 & 103.8 & 102.1 \\
\hline 2020 & 102.5 & 102.3 & 101.4 & 102.5 & 101.7 \\
\hline 2030 & 96.6 & 98.3 & 100.3 & 97.7 & 99.8 \\
\hline 2040 & 95.7 & 96.2 & 99.0 & 95.9 & 98.1 \\
\hline 2050 & 96.0 & 95.9 & 98.1 & 95.9 & 97.1 \\
\hline 2060 & 94.7 & 95.1 & 97.3 & 95.0 & 96.2 \\
\hline New steady state & 94.8 & 94.8 & 94.8 & 94.8 & 94.8 \\
\hline \multicolumn{6}{|c|}{ Case 2. Earnings-weighted labor force and needs-weighted consumption } \\
\hline Initial steady state & 100.0 & 100.0 & 100.0 & 100.0 & 100.0 \\
\hline Initial adjustment & 100.0 & 102.3 & 102.8 & 101.9 & 102.8 \\
\hline \multicolumn{6}{|l|}{ Time path } \\
\hline 2000 & 105.4 & 104.1 & 103.0 & 104.5 & 103.3 \\
\hline 2010 & 104.9 & 104.1 & 102.8 & 104.5 & 103.0 \\
\hline 2020 & 99.4 & 100.4 & 101.5 & 100.2 & 101.1 \\
\hline 2030 & 94.0 & 95.7 & 99.6 & 95.0 & 98.3 \\
\hline 2040 & 93.0 & 93.5 & 97.8 & 93.2 & 96.0 \\
\hline 2050 & 92.5 & 92.7 & 96.3 & 92.6 & 94.5 \\
\hline 2060 & 91.7 & 92.0 & 95.1 & 91.8 & 93.4 \\
\hline New steady state & 91.6 & 91.6 & 91.6 & 91.6 & 91.6 \\
\hline
\end{tabular}

Source: Authors' calculations.

a. Each column is the simulated path of consumption in response to a demographic shock like that which the United States will experience between 1990 and 2060 . The static expectations column is the change in consumption if agents in each period assume that the current level of $\alpha$ and $n$ will persist forever. The perfect foresight columns assume current knowledge of the entire path of demographic change. The initial steady state is the 1990 value of $\alpha$ and $n$.

b. $\beta$ is the substitution elasticity in production; $\sigma$ is the substitution elasticity in consumption.

optimal response to the demographic transition that the United States will undergo over the next seven decades, assuming these changes were unforeseen as of 1990 .

The results of these simulations are shown in table 4 . The level of per capita consumption in the 1990 steady state is normalized to 100 . The first column, the static expectations response, is the change in consump- 
tion if consumers have no foresight about demographic change but rather assume at each date that current conditions will persist forever. It thus corresponds to the consumption path in table 3 . The other four columns assume that consumers in $\mathbf{1 9 9 0}$ have perfect foresight regarding future demographic changes.

For all the parameter values, consumption rises initially in response to the demographic transition, by up to 2.8 percent relative to the steady state implied by 1990 demography. This result is insensitive to the parameter choices we present. ${ }^{27}$ Consumption remains above its 1990 level until 2020 or later. Thus, demographic shifts during the next halfcentury optimally raise present consumption. The initial effect is more pronounced when consumption is less substitutable over time ( $\sigma$ is small) and less pronounced when production is less substitutable over time ( $\beta$ is small).

Figure 7 shows the movements of consumption and capital for the simulations using unit elasticities of substitution in production and consumption. The corresponding saving rate is shown in figure 8 . Consumption initially rises by 2.3 percent. This is followed by a period when capital per effective worker declines, during which consumption continues to increase. The shifting opportunity locus due to the decline in labor force growth ultimately causes an increase in saving and thus in capital intensity, even at the higher level of consumption. After the period of capital deepening, consumption begins to decline. Finally, when the increase in dependency overtakes the favorable effects of the slowing labor force growth, both consumption and capital decline to the new steady state, and saving remains low.

As figure 8 demonstrates, the saving rate falls almost 2 percentage points during the 1990 initial adjustment. It then increases for a few years, though it never attains its initial steady-state value. This increase is due to the increase in the support ratio, which allows both consumption per person and the saving rate to increase. Finally, the saving rate begins to fall toward its new long-run level, equal to the amount of saving necessary to equip the more slowly growing labor force.

We also ran the simulations using the Social Security Administration's alternative I and alternative III, with no substantive changes in results.

27. In addition to the parameter values reported, we have experimented with elasticities in substitution and production up to 10 . For none of these cases is there an initial increase in savings. 
Figure 7. Optimal Consumption and Capital-Labor Trajectory Following Demographic Shock, 1990-2060

Consumption per effective person (index, $1990=100)$

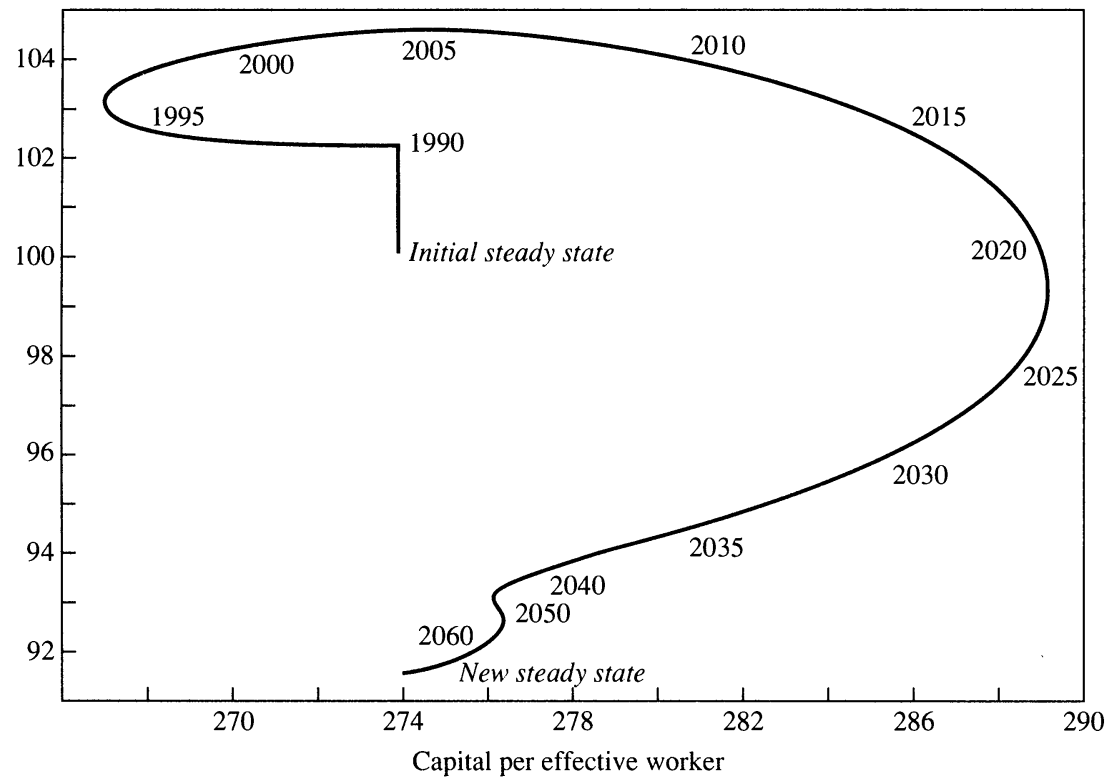

Source: Authors' calculations. Elasticities used are $\beta=1, \sigma=1$. Labor force measure is earnings-weighted ( $L F 2$ ); consumption measure is needs-weighted (CON2). Consumption at the initial steady state is normalized to 100 . The resulting index yields capital per effective worker equal to 274 in the initial steady state.

Consumption rises less with the alternative I assumptions than with our benchmark alternative II assumptions, because the number of dependent children does not decrease as quickly, and more with the alternative III assumptions, where there is an even larger short-run benefit. In all three cases the response to the demographic news is a decrease in saving. We have also experimented with changing capital's share or the assumed initial level of capital intensity in order to vary the discount rate $:{ }^{28}$ Even with a pure discount rate as low as zero, our conclusion that consumption rises following a demographic shock remains valid.

Finally, we explored how consumption would change if we began the simulations in 1970 or 1980 . As table 2 demonstrated, consumption

28. Because the discount factor must equal the marginal product of capital in steady state, and the marginal product of capital is the ratio of capital's share in output to the capital-output ratio, changes in the discount factor have to be accompanied by changes in either capital's share or the capital-output ratio. 
Figure 8. Optimal Saving Rates in Response to Demographic Shock, 1990-2070

Saving rate (percent)



Source: Authors' calculations. Elasticities used are $\beta=1, \sigma=1$. The consumption measure is needs-weighted (CON2); the labor force measure is earnings-weighted $(L F 2)$.

possibilities are higher in 1990 than in any of the three previous decades. Figure 9 shows the deviation of the saving rate from its initial steadystate level after the demographic news. In all of the simulations, saving falls immediately following the demographic news, and is always falling by 2000 . Even in the cases where saving begins to increase in the 1990swhen we begin the simulation in 1980 or 1990-the saving rate is lower throughout the 1990s than the original steady state, and it begins a period of prolonged decline by 2000 .

While these figures help to develop perspective on the recent decline in U.S. saving and investment rates, the actual decline in U.S. national saving from an average of 7.1 percent in the 1970 s to about 2 percent in the late 1980 s is considerably more than our demographic analysis can justify.

The analysis in this section reaches a clear conclusion. For an economy choosing its consumption path in accord with a standard optimal growth model, the right response to the upcoming U.S. demographic change 
Figure 9. Optimal Saving Responses to Demographic Change: Sensitivity to Date of Demographic Discovery ${ }^{a}$

Difference in saving rate from steady state (percent)



Source: Authors' calculations using Board of Trustees of the Federal Old-Age and Survivors Insurance and Disability Insurance Trust Funds (1988).

a. This figure presents the percentage point difference in saving rates from the initial steady state following a demographic shock. The three lines represent saving paths when the simulations are run starting in 1970, 1980, and 1990. These saving paths come from simulations using needs-weighted consumption (CON2) and the earningsweighted labor force $(L F 2)$, and unit elasticities of substitution in both production and consumption $(\beta=1, \sigma=1)$.

would be an increase in consumption and a reduction in national saving. For all plausible combinations of parameter values, the effects of reduced labor force growth and reductions in the number of children exceed the effects of increases in long-run dependency.

\section{Open-Economy Aspects of the Demographic Shift}

Our analysis thus far has focused on the demographic change in the United States. When capital markets are integrated, however, the demographic shift in the United States must be measured not only in absolute terms but relative to the coincident shifts in our major trading partners. This section compares the degree of population aging in 
different nations and extends our earlier simulation model to consider the United States in relation to the other countries in the Organization for Economic Cooperation and Development (OECD). Our earlier finding that, other things being equal, demographic changes justify a reduction in optimal saving is reinforced when we allow for international capital flows, because demographic change is less pronounced in the United States than elsewhere in the OECD.

\section{Relative Rates of Population Aging}

To compare rates of population aging, we use projections by the OECD. ${ }^{29}$ These projections differ in two important ways from the Social Security Administration projections for the United States. First, the OECD treats the 15-19 age group as workers rather than dependents. Second, and more important, the OECD assumes that fertility rates in all countries will converge to the replacement level of 2.1 by 2050 . Because U.S. fertility rates are currently well above those in most of the OECD, this understates the likely contrast between the future U.S. and foreign demographic experiences.

Figure 10 shows the historical and projected elderly dependency ratio for the United States, Japan, and the European Community. ${ }^{30}$ The elderly dependency ratio increases substantially in all countries, with the most rapid increase in Japan. By 2050, even with a 19 percentage point increase in the elderly dependency ratio from 1950 , the U.S. ratio will be roughly 5 percentage points lower than those of the other countries.

Figure 11 shows the path of support ratios corresponding to the $L F 1$ and CON1 assumptions. The broad outlines for all three regions are similar. All have higher support ratios in 1990 than in 1960, and all will have much lower support ratios by the middle of the next century than they do today. The ultimate level of U.S. dependency will be lower than that abroad.

Two differences in these indexes are notable, however. First, the United States will be better off for the next two decades than it is now, while the other countries experience declines in the support ratio

29. OECD (1988).

30. The multicountry index is a GDP-weighted average of the indexes for the individual countries. 
Figure 10. Actual and Projected Elderly Dependency Ratios, United States, Japan, and European Community, 1950-2050

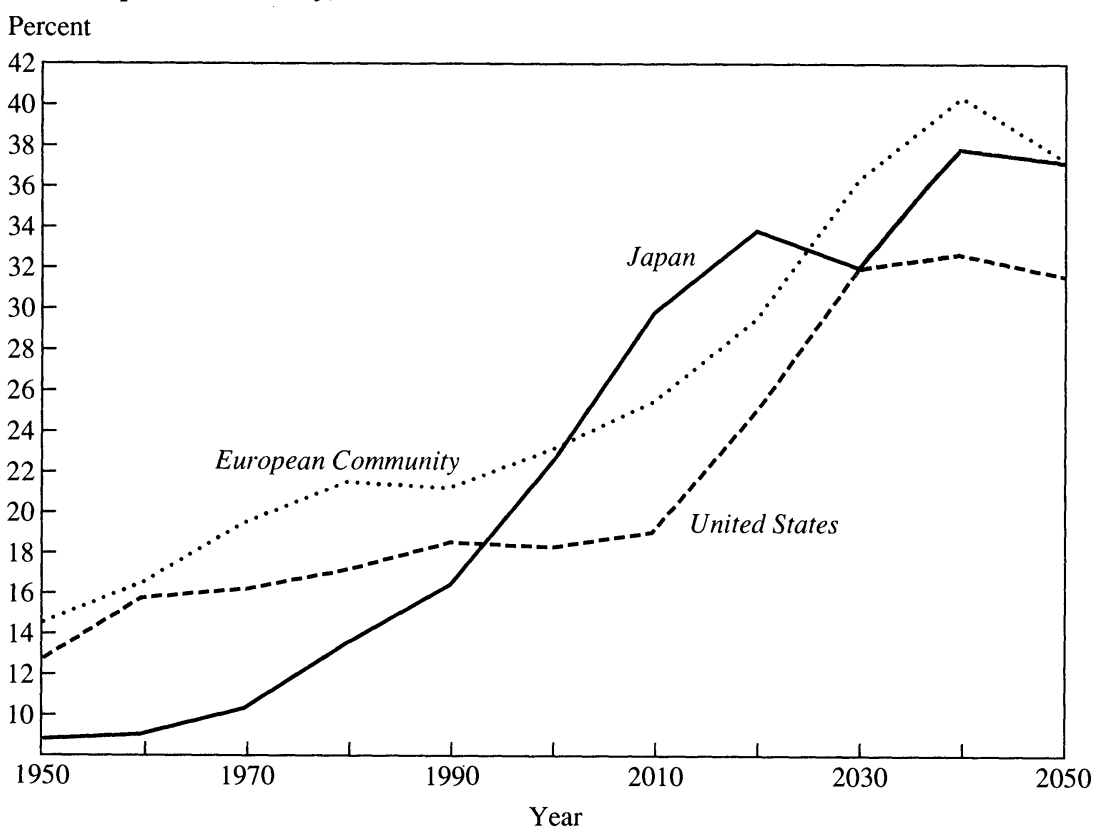

Source: OECD (1988). Working-age population includes all those aged 15-64.

beginning in 1990. Second, the U.S. and EC dependency ratios are driven principally by fertility changes, while the Japanese changes are driven to a much larger extent by reductions in mortality. ${ }^{31}$ The decline in the support ratio in the 1950s in the United States and in the 1960s in the EC is due to increased numbers of children; the rise in the support ratio throughout the postwar period in Japan, in contrast, is caused by reduced mortality at middle and older ages. Because the labor force grows faster when fertility is higher, the reduction in labor force growth over the next several decades, and thus the consumption dividend from reduced investment requirements, will be larger in the United States and the European Community than in Japan.

To evaluate the size of the demographic transition abroad, table 5 reports the optimal consumption and saving responses to projected

31. OECD (1988) presents evidence on the importance of fertility and mortality declines for the different countries. 
Figure 11. Actual and Projected Support Ratios, United States, Japan, and European Community, 1950-2050

Support ratio $(1990=1)$

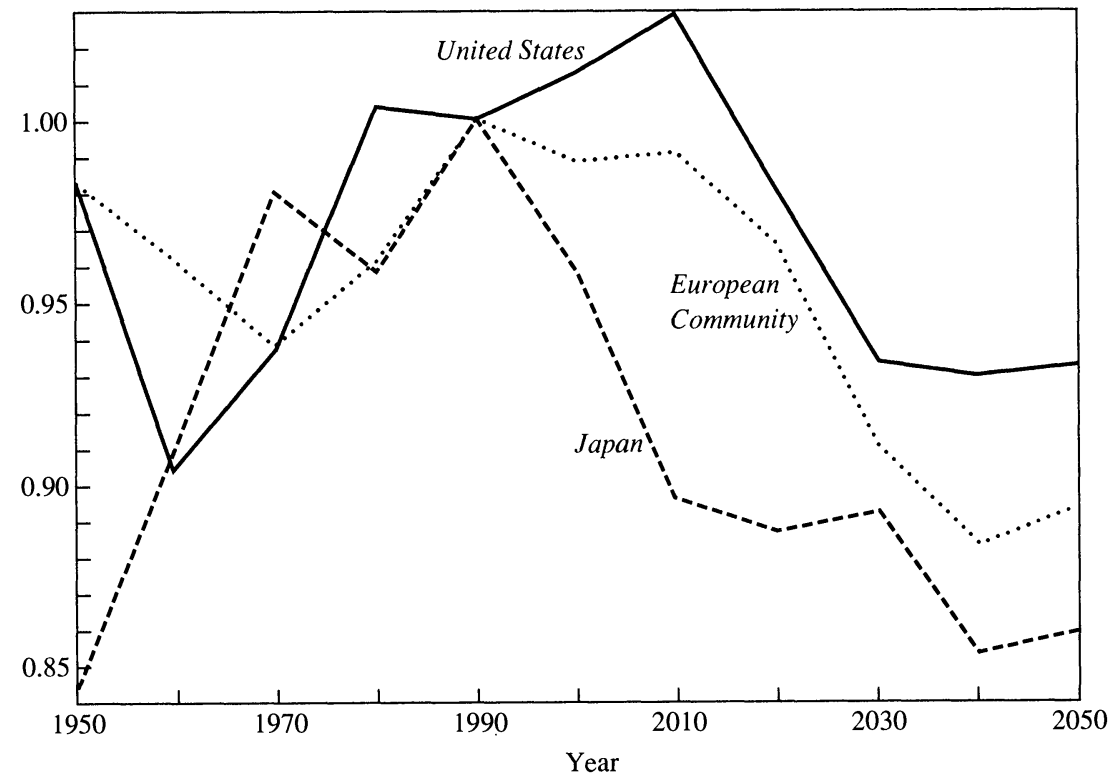

Source: OECD (1988) The consumption measure is total population (CON1). The labor force measure is the population 15-64 (LF1).

demographic changes in the United States, Japan, the European Community, the non-U.S. OECD, and the total OECD. ${ }^{32}$ These consumption paths are simulated using the model of the previous section. For the United States, consumption rises only slightly initially, continues increasing until 2010, and then declines to the new steady state. This consumption increase is accompanied by an increased saving rate, however, since the relative increase in the working-age population increases output per person by more than consumption per person.

For Japan, the coming demographic changes reduce optimal con-

32. The table uses the case of unit elasticities of substitution and production. We assume that depreciation rates and rates of labor-augmenting technical progress are equal in all countries and are the same as the Social Security Administration forecasts for the United States. The assumption of equal productivity growth is obviously wrong but probably does not have a large impact on estimates of the change in saving due to changes in demographic structure. 
Table 5. Autarky Response of Consumption and Saving to Demographic Shocks, United States and Various Nations, 1990-2050

\begin{tabular}{|c|c|c|c|c|c|}
\hline \multirow[b]{2}{*}{ Item } & \multicolumn{5}{|c|}{ Country } \\
\hline & $\begin{array}{l}\text { United } \\
\text { States }\end{array}$ & Japan & $\begin{array}{c}\text { European } \\
\text { Community }\end{array}$ & $\begin{array}{c}\text { Non-U.S } \\
\text { OECD }\end{array}$ & $\begin{array}{l}\text { Total } \\
\text { OECD }\end{array}$ \\
\hline & \multicolumn{5}{|c|}{ Consumption response } \\
\hline Initial steady state & 100.0 & 100.0 & 100.0 & 100.0 & 100.0 \\
\hline Initial adjustment & 100.1 & 99.2 & 100.1 & 100.0 & 100.1 \\
\hline \multicolumn{6}{|l|}{ Time path } \\
\hline 2000 & 100.6 & 97.2 & 99.7 & 99.3 & 99.8 \\
\hline 2010 & 101.5 & 92.2 & 98.8 & 97.8 & 99.2 \\
\hline 2020 & 99.1 & 89.0 & 97.1 & 95.5 & 97.0 \\
\hline 2030 & 94.4 & 88.5 & 92.8 & 92.1 & 93.0 \\
\hline 2040 & 92.0 & 86.3 & 89.1 & 88.8 & 89.9 \\
\hline 2050 & 92.1 & 84.8 & 88.2 & 87.9 & 89.1 \\
\hline \multirow[t]{2}{*}{ New steady state } & 92.3 & 84.4 & 87.9 & 87.8 & 89.0 \\
\hline & \multicolumn{5}{|c|}{ Saving rate response } \\
\hline Initial adjustment & -0.1 & 0.7 & -0.1 & 0.0 & 0.0 \\
\hline \multicolumn{6}{|l|}{ Time path } \\
\hline 2000 & 0.1 & -1.4 & -0.9 & -1.0 & -0.6 \\
\hline 2010 & 0.5 & -3.0 & -0.7 & -1.1 & -0.5 \\
\hline 2020 & -1.4 & -2.6 & -1.5 & -1.8 & -1.6 \\
\hline 2030 & -2.4 & -1.3 & -2.8 & -2.5 & -2.5 \\
\hline 2040 & -1.5 & -3.1 & -2.9 & -2.9 & -2.3 \\
\hline 2050 & -1.4 & -1.5 & -0.8 & -1.2 & -1.3 \\
\hline New steady state & -1.5 & -1.3 & -0.7 & -1.1 & -1.3 \\
\hline
\end{tabular}

Source: OECD (1988) and authors' calculations

a. The values in the table are the optimal consumption and saving paths for each country without international capital flows. We use needs-weighted consumption (CON2) and the unweighted labor force ( $L F 1)$. Consumption is relative to the initial steady state, which is normalized to 100 . Saving paths are defined as the percentage point difference between the saving rate along the path and the initial steady state. The elasticities of substitution in production and consumption both equal unity.

sumption initially by just under 1 percent, and consumption continues to decline throughout the next 60 years, even as the saving rate declines. For the European Community, there is also a slight increase in consumption, but by 2000 consumption is lower, and continues to decline throughout the next half-century. This pattern of declining consumption after a small increase in initial consumption carries over to the non-U.S. OECD and total OECD simulations.

The initial decrease in the saving rate in the United States and the increase in the non-U.S. OECD imply that in an open economy, capital would initially flow from the non-U.S. OECD to the United States. After the initial change in saving, however, capital flows are more difficult to 
predict. In addition to the change in saving rates in the autarky case, the countries also have different changes in labor force growth rates, and thus in investment requirements. Because the desired capital inflow depends on the difference between saving and investment requirements, looking at saving rates or consumption alone does not indicate whether each country would borrow or lend. To address this issue, we turn next to simulations that allow for capital mobility.

\section{A Two-Country Simulation Model}

Our open-economy simulations aggregate the European Community, Japan, and the other countries of the OECD to form a non-U.S. OECD index. Figures 12 and 13 show the support ratio and labor force growth rates for the United States and this aggregate. The support ratios are consistent with those in figure 11. The United States has a 5 percentage point higher support ratio in 2050 than the non-U.S. OECD, and unlike the rest of the OECD has a rising support ratio over the next two decades. By 2050 the labor force in both areas is projected to stabilize, not grow. Between now and then they fluctuate, but with U.S. labor force growth always higher.

To assess the optimal response of U.S. saving in an open-economy context, we extend the model of the previous section to allow for capital mobility. We distinguish asset ownership from asset location by denoting period $t$ asset ownership per person in country 1 by $a_{1, t}$. Asset accumulation is given by

$$
\dot{a}_{1, t}=w_{t}+a_{1, t}\left(r_{t}-n_{1, t}\right)-\left(c_{1, t} / \alpha_{1, t}\right),
$$

where the wage, $w_{t}$, and the interest rate, $r_{t}$, are equalized across countries. The labor force growth rate, the support ratio, and the level of per capita consumption can differ across countries and therefore have both time and country subscripts.

The common capital-labor ratio is a weighted average of asset holdings in the two nations:

$$
k_{t}=\theta_{1, t} a_{1, t}+\left(1-\theta_{1, t}\right) a_{2, t},
$$

where $\theta_{1, t}$ is country 1's share of world population. From equation 16 we derive the capital accumulation constraint for the two-country model:

$$
\dot{k}_{t}=\dot{\theta}_{1, t}\left(a_{1, t}-a_{2, t}\right)+\theta_{1, t} \dot{a}_{1, t}+\left(1-\theta_{1, t}\right) \dot{a}_{2, t} .
$$


Figure 12. Actual and Projected Support Ratios, United States and Non-U.S. OECD, 1960-2050

Support ratio $(1990=1)$

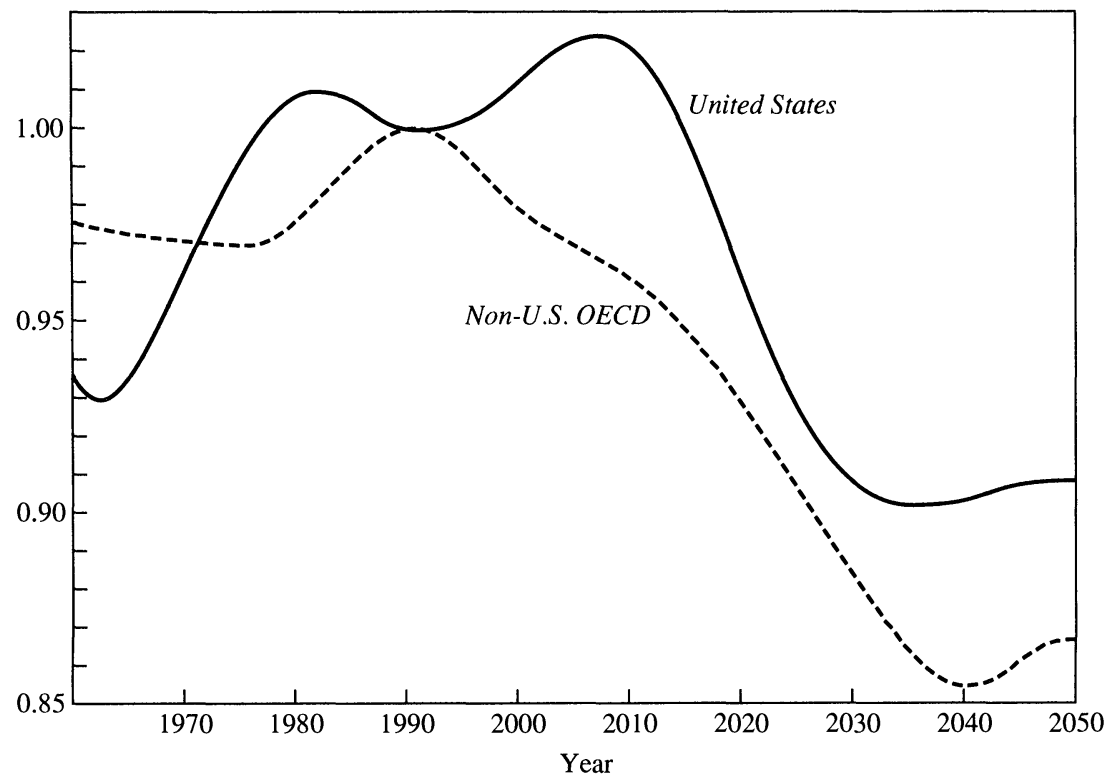

Source: Authors' calculations based on data in OECD (1988). Non-U.S. OECD includes all OECD countries except the United States, weighted by GDP. The consumption measure is needs-weighted (CON2), with the same weights as for the United States. The labor force is the population 15-64 (LF1).

This constraint replaces equation 10 in the one-country model. The optimal consumption profile (equation 11) and the steady-state savinginvestment relation (equation 12) are identical to those in the one-country case.

We calibrate the two-country model assuming that both countries have Cobb-Douglas production functions and logarithmic utility functions. We assume that one nation is the United States and the other is the non-U.S. OECD, and set the relative labor force in the United States at four-tenths of the two-country total, roughly the value of the productivity-weighted U.S. labor force share for 1990. In addition, we begin the simulations assuming no net foreign investment position. ${ }^{33} \mathrm{We}$ also assume equal rates of technological progress and equal discount rates in the two countries.

33. This corresponds to the average U.S. net foreign asset position during the 1980 s, but understates foreign holdings of U.S. assets at the beginning of the 1990s. 
Figure 13. Actual and Projected Growth Rate of Labor Force, United States and Non-U.S. OECD, 1960-2050

Annual growth rate (percentage points)

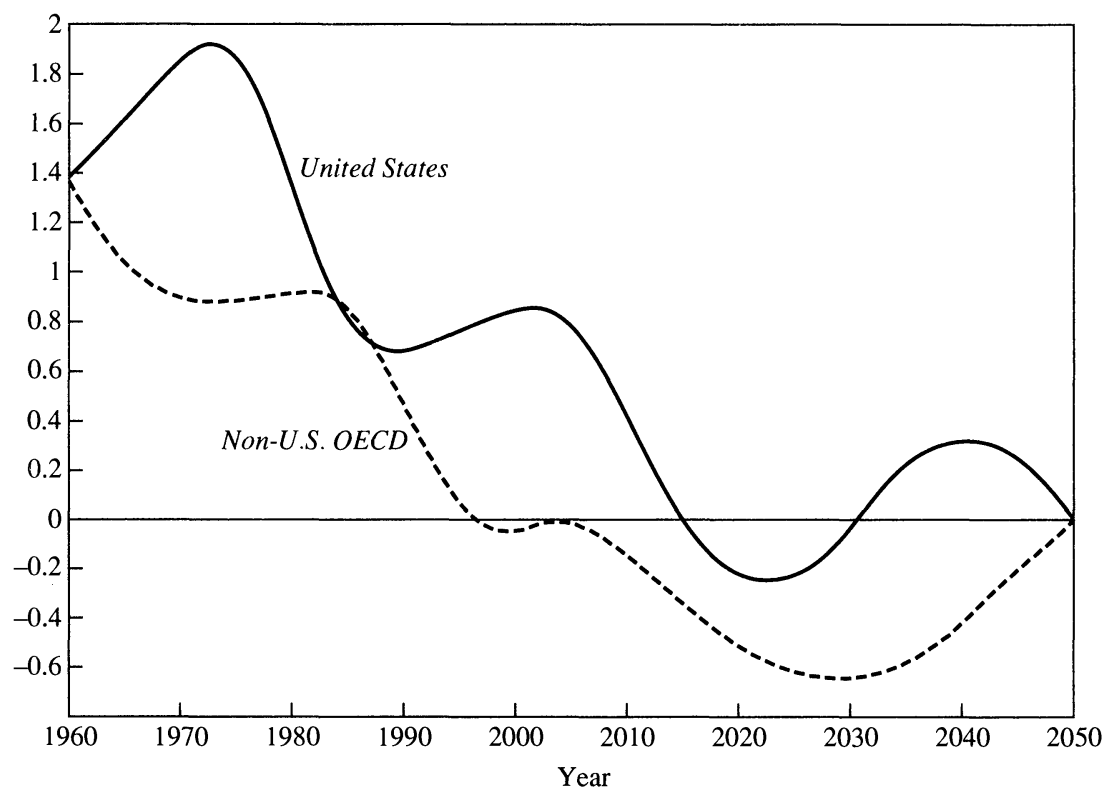

Source: Same as figure 12 .

Table 6 presents the two-country simulation results. We normalize consumption to be 100 initially in both countries. While the shape of the consumption response is similar in the open- and closed-economy cases, the size of the responses is different. For the United States, the closedeconomy analysis suggests a 0.1 percent consumption increase relative to the 1990 steady state. With capital flows between the relatively slowly aging United States and the more rapidly aging rest of the OECD, however, the U.S. consumption increase is 1 percent of the 1990 benchmark. Consumption in the United States increases more in the open-economy case because high saving elsewhere in the world reduces the rate of return to capital, inducing a positive shock to the value of human wealth. ${ }^{34}$

34. Although we assume that utility is logarithmic, the interest elasticity of saving is positive. When interest rates increase, holding wealth constant, saving is unaffected. However, with interest rates higher, the present discounted value of labor income decreases, and hence consumption falls. Wages in the United States also increase in the short run. 
Table 6. Effect of Demographic Shock on Consumption and Foreign Capital Ownership, United States and Non-U.S. OECD, 1990-2050 ${ }^{\mathrm{a}}$

\begin{tabular}{lccccc}
\hline & \multicolumn{2}{c}{ United States } & & \multicolumn{2}{c}{ Non-U.S. OECD } \\
\cline { 2 - 3 } \cline { 5 - 6 } \multicolumn{1}{c}{ Item } & $\begin{array}{c}\text { Consump- } \\
\text { tion }\end{array}$ & $\begin{array}{c}\text { Foreign } \\
\text { capital } \\
\text { ownership } \\
\text { (percent) }\end{array}$ & & $\begin{array}{c}\text { Consump- } \\
\text { tion }\end{array}$ & $\begin{array}{c}\text { Foreign } \\
\text { capital } \\
\text { ownership } \\
\text { (percent) }\end{array}$ \\
\hline Initial steady state & 100.0 & 0.0 & 100.0 & 0.0 \\
Initial adjustment & 101.0 & 0.0 & & 99.4 & 0.0 \\
Time path & 100.8 & -5.5 & & 99.2 & 3.7 \\
2000 & 100.2 & -6.4 & & 98.7 & 4.7 \\
2010 & 97.9 & -3.5 & & 96.4 & 2.6 \\
2020 & 93.9 & -4.7 & & 92.4 & 3.7 \\
2030 & 91.0 & -7.9 & & 89.6 & 6.7 \\
2040 & 90.5 & -8.7 & 89.1 & 7.7 \\
2050 & 90.5 & -8.7 & 89.1 & 7.7 \\
New steady state & & & & &
\end{tabular}

Source: OECD (1988) and authors' calculations.

a. The table shows the results from the open-economy demographic simulation. We use the needs-weighted measure for consumption $(C O N 2)$ and the unweighted labor force $(L F 1)$. Consumption is normalized to 100 in the initial steady state. Foreign capital ownership is the percentage of assets in each country owned by foreigners. It is initially zero in both countries. The elasticities of substitution in production and consumption both equal unity.

To finance the additional consumption indicated in the simulations, the United States runs a current account deficit. Figure 14 shows the path of net national saving and net investment, and, as residual, the current account. For about 15 years, the United States runs current account deficits, so that more than 6 percent of U.S. assets are owned by foreigners in 2010. High saving for the subsequent 15 years results in current account surpluses and reduces foreign capital ownership to 3.5 percent. Past 2020, however, with the rapid increase in the number of elderly, the United States again runs current account deficits, so that in the steady state almost 9 percent of U.S. assets are owned by foreigners.

For the non-U.S. OECD, consumption declines 0.6 percent when trade with the United States is permitted. The availability of investment projects in the United States means that higher saving in the short run will not depress rates of return by as much as in the closed-economy case.

The open- and closed-economy cases yield different consumption levels in both the short run and the steady state. In the open-economy 
Figure 14. Net Saving and Investment Rates, United States, from Two-Country Simulations, 1990-2050

Percent of GNP

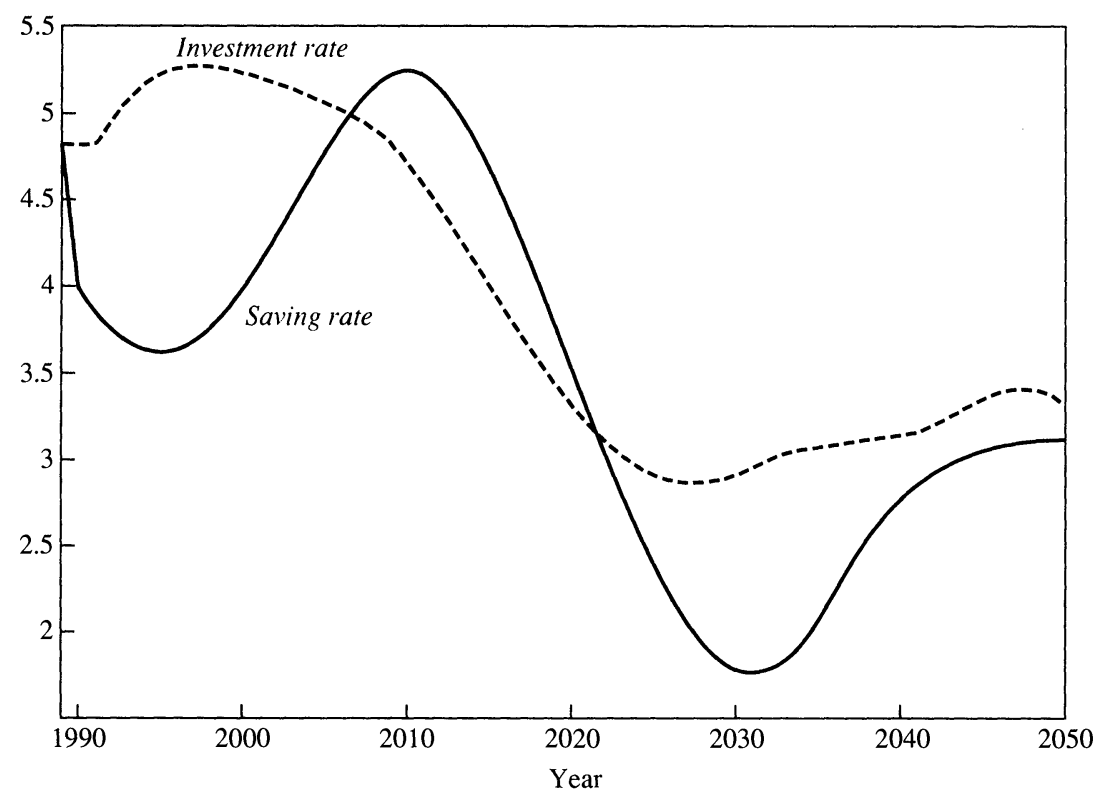

Source: Authors' calculations and OECD (1988).

case, U.S. consumption is higher in the early stage of the transition because of the availability of foreign capital. The resulting decrease in asset accumulation translates into a 1.8 percentage point reduction in steady-state consumption from the closed-economy simulation. For the non-U.S. OECD, the effect is reversed: greater capital accumulation along the transition path leads to steady-state consumption 1.3 percentage points higher than in the autarky steady state.

These results suggest two conclusions. First, the pattern of demographic change in other developed nations can have a large effect on the optimal consumption response to demographic change in the United States. The importance of these effects depends critically on the degree of capital market integration. Second, because the United States is aging more slowly than other OECD nations, the optimal consumption response in the open economy entails higher initial consumption than in the autarky case and thus a current account deficit. 


\section{Demographic Change and Productivity Growth}

The foregoing calculations assume that demographic changes affect productivity only by causing changes in capital intensity. The rate of technical change, or equivalently of total factor productivity, is assumed to be independent of demographic developments. But if demographic factors affect technical change, the implications could be quite significant, both for living standards and for optimal capital accumulation.

There are several potential links between demographic developments and the rate of technological change. One argument, stressed recently by Julian Simon and Ben Wattenberg, holds that slow population growth reduces the rate of technical progress. ${ }^{35}$ The argument has two strands. First, a rapidly growing population enlarges the market for capital goods (the Solow effect noted above), making innovation more profitable by permitting greater spreading of fixed costs. As population growth slows, innovation becomes less profitable. Second, as the share of the population that is young and innovates declines, the aging society loses some of its "dynamism" and experiences slower technical change. As described by French demographer Alfred Sauvy, such a future would hold "a society of old people, living in old houses, ruminating about old ideas." 36

A more optimistic argument, advanced by H. J. Habakkuk, is that incentives to innovate are strongest when labor is scarce.$^{37}$ Habakkuk argued that industrialization proceeded faster in America than in England because attractive agricultural opportunities raised the price of labor in the United States relative to that in England, where labor was abundant and less expensive. Paul Romer has formalized this argument and used it to explain the apparent tendency for abnormally rapid U.S. productivity growth in periods of relatively slow labor force growth. ${ }^{38}$

The relative importance of these mechanisms can only be assessed empirically. Unfortunately, there are no ideal experiments for considering the effects of demographic change on productivity growth. Below we draw on the differing demographic experiences of relatively high-

35. Simon (1981) and Wattenberg (1987).

36. Wattenberg $(1987$, p. 65$)$.

37. Habakkuk (1962).

38. Romer (1990). 
income countries to assess the likelihood that an aging population will lead to economic stagnation.

\section{Evidence on Productivity and Demographic Composition}

Our empirical work uses the 1960-85 international comparison data of Robert Summers and Alan Heston. ${ }^{39}$ Unfortunately, data on total factor productivity are not available for a wide sample of countries. Instead, we study the relation between labor force growth and labor productivity growth. ${ }^{40}$

We selected countries with 1960 labor productivity at least 30 percent of U.S. productivity (we use income per worker as our productivity measure) and excluded the OPEC countries, thus generating a sample of 29 countries. Selecting on initial income avoids the bias of including only countries that have experienced large productivity growth, as Bradford DeLong highlights. ${ }^{41} \mathrm{We}$ omit countries with very low initial productivity because the role of labor force growth may be very different in pre-industrial societies. Japan is omitted because its productivity was only 25 percent of U.S. productivity in 1960 .

Figure 15 plots annual productivity growth and annual labor force growth during 1960-85. The data show a strong negative correlation. Slower-growing countries, including most European nations, exhibit above-average productivity growth, while more rapidly growing countries such as Canada and Australia have lower productivity growth.

To control for additional factors affecting growth, we estimate crosssection regressions of the form:

$$
\begin{aligned}
\ln \left(y_{1, i} / y_{0, i}\right) / T= & \alpha_{0}+\alpha_{1} \ln \left(L F_{1, i} / L F_{0, i}\right) / T \\
& +\alpha_{2} \ln \left(y_{0, i}\right)+\alpha_{3}(I / Y)_{i}+\epsilon_{i},
\end{aligned}
$$

where $y_{1, i}$ and $y_{0, i}$ are, respectively, final and initial output per labor force member; $L F_{1, i}$ and $L F_{0, i}$ are the final and initial labor force; $(I / Y)_{i}$ is the average investment rate during the sample period; $i$ denotes the country; and $T$ is the length of the sample period. The investment rate is included to control for changes in capital that affect labor productivity but not

39. Summers and Heston (1990).

40. We present limited evidence below suggesting that the difference between labor productivity and total factor productivity does not have a large effect on our results.

41. DeLong (1988). 
Figure 15. Productivity Growth and Labor Force Growth, Selected Countries, 1960-85 ${ }^{\text {a }}$ Productivity growth (percent annually)

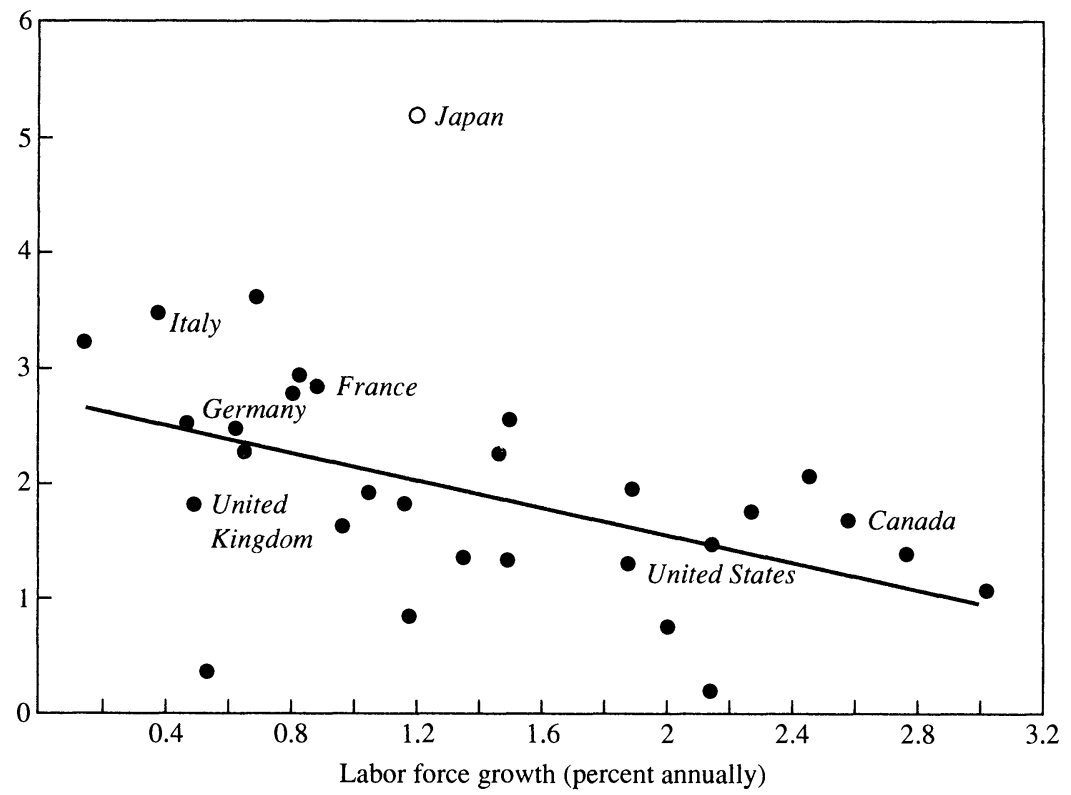

Source: Authors' calculations based on data in Summers and Heston (1990). The G-7 countries are labeled on the figure.

a. Japan is included in the figure but not in the regression line.

total factor productivity. Initial income is included to capture the possibility that lagging countries grow more rapidly as they converge toward leading ones. Productivity growth and labor force growth are expressed at annual rates.

The upper panel of table 7 reports ordinary least squares estimates of equation 18. The coefficients in the bivariate regressions, analogous to figure 15 , imply that a 1 percentage point decrease in the annual labor force growth rate raises productivity growth by 0.62 percentage point a year. Controlling for the initial level of productivity and investment rates has little effect on the labor force growth coefficient, with the estimates still negative ( -0.64$)$ and large. The data also suggest that more rapid investment leads to faster productivity growth, although there is no evidence of productivity convergence for this sample.

We estimated equation 18 with other samples of countries, with similar results. If we include the six OPEC countries with 1960 produc- 
Table 7. Demographic Change and Productivity Growth, 1960-85, Various Periods ${ }^{\mathrm{a}}$

\begin{tabular}{|c|c|c|c|c|c|c|}
\hline \multirow[b]{2}{*}{ Period } & \multicolumn{2}{|c|}{ No controls } & \multicolumn{4}{|c|}{ With controls } \\
\hline & $\begin{array}{l}\text { Labor force } \\
\text { growth }\end{array}$ & $\overline{R^{2}}$ & $\begin{array}{l}\text { Labor force } \\
\text { growth }\end{array}$ & $\begin{array}{c}\text { Logarithm } \\
\text { of initial } \\
\text { productivity }\end{array}$ & $\begin{array}{l}\text { Investment } \\
\text { rate }\end{array}$ & $\bar{R}^{2}$ \\
\hline \multicolumn{7}{|c|}{ Ordinary least squares estimates } \\
\hline $1960-85$ & $\begin{array}{c}-0.617 \\
(0.179)\end{array}$ & 0.281 & $\begin{array}{c}-0.637 \\
(0.161)\end{array}$ & $\begin{array}{c}-0.346 \\
(0.434)\end{array}$ & $\begin{array}{c}0.063 \\
(0.022)\end{array}$ & 0.421 \\
\hline $1960-73$ & $\begin{array}{c}-1.061 \\
(0.245)\end{array}$ & 0.389 & $\begin{array}{r}-1.044 \\
(0.232)\end{array}$ & $\begin{array}{r}-0.730 \\
(0.647)\end{array}$ & $\begin{array}{c}0.064 \\
(0.028)\end{array}$ & 0.460 \\
\hline $1973-85$ & $\begin{array}{r}-0.258 \\
(0.198)\end{array}$ & 0.025 & $\begin{array}{r}-0.295 \\
(0.195)\end{array}$ & $\begin{array}{c}0.154 \\
(0.546)\end{array}$ & $\begin{array}{c}0.075 \\
(0.031)\end{array}$ & 0.175 \\
\hline Fixed effects & $\begin{array}{c}-0.903 \\
(0.477)\end{array}$ & 0.085 & $\begin{array}{c}-0.446 \\
(0.355)\end{array}$ & $\begin{array}{c}-6.290 \\
(1.177)\end{array}$ & $\begin{array}{c}0.032 \\
(0.057)\end{array}$ & 0.600 \\
\hline \multicolumn{7}{|c|}{ Instrumental variables estimates } \\
\hline $1960-85$ & $\begin{array}{c}-0.711 \\
(0.216)\end{array}$ & $\ldots$ & $\begin{array}{r}-0.742 \\
(0.189)\end{array}$ & $\begin{array}{r}-0.337 \\
(0.438)\end{array}$ & $\begin{array}{c}0.064 \\
(0.022)\end{array}$ & $\cdots$ \\
\hline $1960-73$ & $\begin{array}{r}-0.977 \\
(0.297)\end{array}$ & $\ldots$ & $\begin{array}{r}-0.956 \\
(0.272)\end{array}$ & $\begin{array}{r}-0.763 \\
(0.651)\end{array}$ & $\begin{array}{c}0.064 \\
(0.028)\end{array}$ & $\ldots$ \\
\hline $1973-85$ & $\begin{array}{c}-0.436 \\
(0.272)\end{array}$ & . & $\begin{array}{c}-0.610 \\
(0.296)\end{array}$ & $\begin{array}{r}-0.150 \\
(0.610)\end{array}$ & $\begin{array}{c}0.085 \\
(0.033)\end{array}$ & $\cdots$ \\
\hline Fixed effects & $\begin{array}{r}-0.840 \\
(1.151)\end{array}$ & $\ldots$ & $\begin{array}{c}0.332 \\
(1.440)\end{array}$ & $\begin{array}{r}-7.273 \\
(2.174)\end{array}$ & $\begin{array}{c}-0.017 \\
(0.107)\end{array}$ & $\cdots$ \\
\hline
\end{tabular}

Source: Authors' calculations based on data in Summers and Heston (1990).

a. The dependent variable is the annual productivity growth rate. The labor force growth rate and investment rate are both annual rates. The sample consists of the 29 non-OPEC countries with 1960 income per worker above 30 percent of the U.S. level. The upper panel reports ordinary least squares estimates. The lower panel instruments for the growth rate of the labor force with the growth rate of the population. Standard errors are in parentheses; $\bar{R}^{2} \mathrm{~s}$ are adjusted for degrees of freedom.

tivity above 30 percent of the U.S. level, the coefficient in the multivariate regression rises to $-0.517(0.144)$. If we limit the sample to countries with 1960 productivity at least 50 percent of that in the United States, the coefficient becomes $-0.263(0.192)$. If we consider the current OECD countries, the coefficient is $-0.372(0.161)$. Finally, if we include all 114 countries in the Summers and Heston data with at least 20 years of data, the coefficient becomes -0.507 (0.159).

Dividing the period 1960-85 into two shorter intervals, 1960-73 and 1973-85, shown in the second and third rows of the upper panel, allows us to examine the importance of the productivity slowdown in the mid1970s. The results from these regressions are consistent with those from the full sample, although the evidence is stronger in the 1960-73 period. In the earlier period, the coefficient $(-1.044)$ is much larger and still statistically significantly different from zero. In the post-1973 period, the coefficient falls to -0.295 and is no longer statistically significant. 
The fourth row of the table presents the results of treating the two sample periods as a panel and estimating a fixed-effects regression. This specification controls for other factors that can explain persistent differences in growth rates across countries but that are not included in our set of explanatory variables. The results are qualitatively similar to those without the fixed effects. The coefficient in the multivariate regression $(-0.446)$ is within the range of the estimates for the two sample periods, although the coefficient is not statistically significantly different from zero when we control for initial income and the investment rate.

The lower panel of the table reports instrumental variables estimates of the same equations, using the population growth rate as an instrument for labor force growth. If rapid productivity growth leads to less rapid increases in labor force participation, the ordinary least squares estimates will be biased, but the instrumental variables regressions will not. The instrumental variables estimates strongly confirm the ordinary least squares estimates. In the 1960-85 regression, the coefficient on labor force growth becomes more negative in the instrumental variables regression (-0.742) and is still statistically significant. The coefficients on the other variables, in contrast, change little.

As the second and third rows of the bottom panel suggest, this is principally due to a more pronounced negative relation between labor force growth and productivity growth during 1973-85. This is consistent with Richard Freeman's claim that the decline in productivity growth in post-1973 Europe discouraged labor force participation, leading to a positive bias in the coefficient on labor force growth rates. ${ }^{42}$

The final row presents the results for the instrumental variables regression with the fixed-effects specification. While the coefficient in the bivariate regression is similar to the ordinary least squares estimate, the coefficient in the multivariate regression is positive. In both cases, the coefficients on labor force growth are not statistically different from zero.

Because reductions in the labor force growth rate tend to increase capital intensity, one would expect them to be associated with increases in labor productivity growth even if they had no impact on technical change. ${ }^{43} \mathrm{We}$ doubt that the equations in table 7 are primarily picking up

42. Freeman (1988).

43. Mankiw, Romer, and Weil (1990) explore this possibility with particular attention to the role of human capital accumulation. 
this effect for two reasons. First, its theoretical magnitude is much smaller than the effects implied by the cross-country equations. Over a 25-year period, a 1 percentage point reduction in labor force growth holding the saving rate constant would raise labor productivity by at most 0.17 percentage point assuming a Cobb-Douglas production function with a 67 percent labor share ${ }^{44}$ Second, for a small sample of OECD countries with available data (18 countries) we estimated productivity growth equations using both labor productivity and total factor productivity and found only negligible differences in the results. ${ }^{45}$

These regressions imply substantively large effects of demographic change on future growth. Because the annual labor force growth rate is predicted to fall by about 1 percentage point between 1990 and 2050, with most of the change occurring between 1990 and 2010, our estimates imply an increase of about 0.6 percentage point in annual productivity growth. Such effects are large enough to offset the decline in living standards that we presented above. Even a 0.2 percentage point increase in annual productivity growth between 1990 and 2040 would offset the roughly 10 percent decrease in per capita consumption as a result of rising dependency burdens over that period. Thus, even if the effects are much smaller than those from our regressions, they are likely to have a large impact on future living standards.

The regressions thus far present little evidence for the more pessimistic view of demographic change. It may be, however, that part of the effect of demographic change occurs through the investment rate. If slower labor force growth reduces the rate of innovation because of decreased demand for capital goods, that will show up as a positive effect of investment rates on productivity growth, rather than as an effect of labor force growth.

To consider this hypothesis, we reestimated the equations in table 7 without controlling for the rate of investment. The results change little from those reported. For the full time period, for example, the coefficient

44. The predicted effect is this large only if the base year for our observations (1960) is the first year of the new labor force growth rates. If the countries were already in steady state with different labor force growth rates, there would be no predicted effect on productivity from this explanation.

45. Without controls for initial productivity and investment rates, the coefficient on the growth rate of the labor force is $-0.788(0.207)$ in the equation for labor productivity and $-0.696(0.257)$ in the equation for total factor productivity. In the multivariate regression, the coefficients are $-0.305(0.216)$ and $-0.259(0.324)$ in the two equations. 
on labor force growth falls only slightly, from $-0.637(0.161)$ to -0.617 $(0.182)$. In no case does the coefficient on labor force growth fall substantially, and in many cases it becomes more important.

It is also possible that our measure of demographic change is not the best measure for examining the productivity consequences of changes in the population structure. The argument that older work forces are less innovative than their younger counterparts suggests that a variable like the average age of the work force is a more direct measure of demographic conditions. Our measure of labor force growth rates is only partly correlated with this type of demographic variable.

We explored this possibility by adding the average age of the labor force to the equations in table $7 .{ }^{46}$ In the basic specification in the first row of the table, when the average age variable is included, the coefficient on the labor force growth rate declines to $-0.483(0.225)$, and that on the average labor force age is $0.135(0.138)$. Neither the coefficient on initial productivity nor that on the investment rate changes substantially. Similar conclusions emerge for the other specifications. ${ }^{47}$

To the extent that the labor scarcity hypothesis is correct, it reinforces our conclusion that the maturing of the labor force expands society's opportunities. Faster productivity growth has a theoretically ambiguous effect on the level of current consumption, however. It tends to increase consumption today because of the income effect of increased output, but this effect can be offset by a substitution effect from the increased investment return as the effective supply of labor grows more quickly.

To evaluate these effects for current consumption decisions, we calculated the optimal consumption path when productivity growth changes over time. We assumed that each percentage point decrease in labor force growth increases productivity growth by 0.5 percentage point, a number in the range of those in table 7 . Figure 16 shows the resulting consumption path, as well as the consumption path without the

46. To account for changes in the average age of the labor force over the time period of our productivity growth measurements, we defined the average labor force age over any period as the mean of the average age at the endpoints of the period.

47. We intend to explore these issues further in subsequent work. Preliminary results suggest that the evidence for beneficial effects of slow labor force growth is much weaker for the 1870-1960 period than for the post-1960 period. This may be a consequence of the simultaneity caused by much larger immigration flows in the early period. At this point, it seems fair to conclude that there is no international evidence for the dynamism hypothesis that more rapid population growth or a younger population raises productivity, and some evidence for the contrary labor scarcity hypothesis. 
Figure 16. Consumption Response with Induced Productivity, United States, 1990-2065 Per capita consumption (index, $1990=100$ )

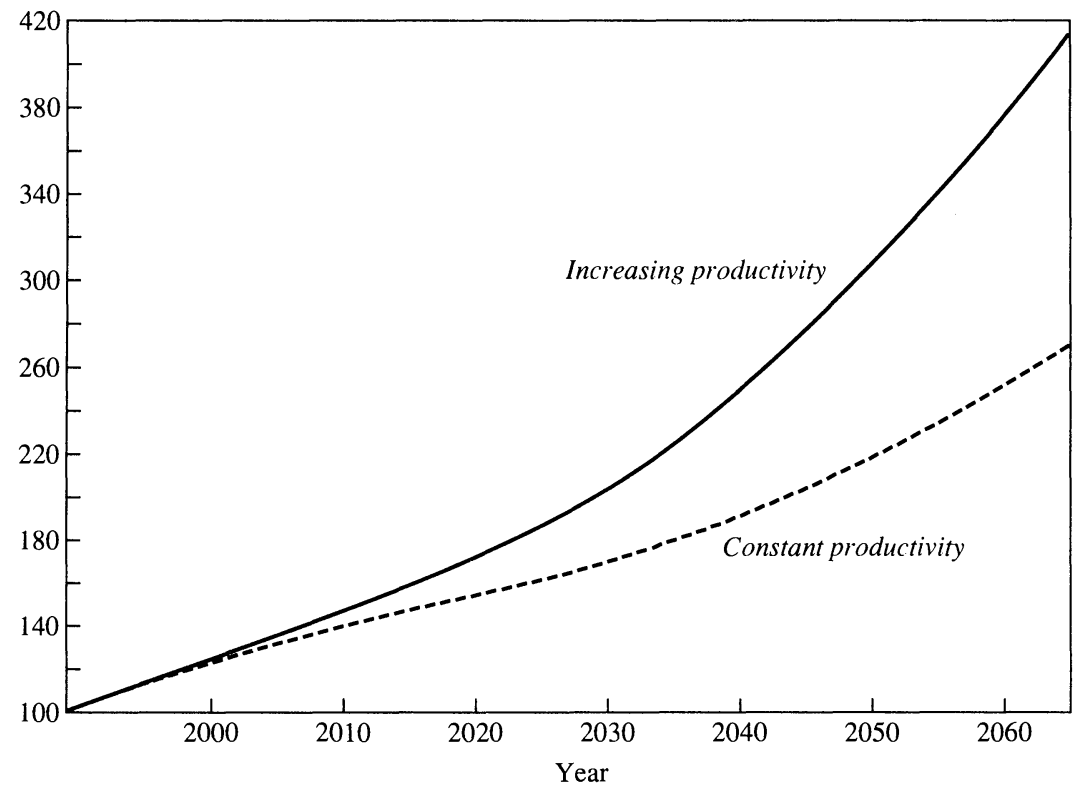

Source: Authors' calculations. For increasing productivity, it is assumed that productivity grows 0.5 percent for each 1 percent decline in annual labor force growth. The consumption measure is needs-weighted (CON2), and the labor force is earnings-weighted $(L F 2)$. The simulations assume unit elasticities of substitution in production and consumption.

productivity effects, following a demographic shock like those examined in the previous sections. ${ }^{48}$ The effect of increased productivity growth is to increase current consumption even more, by an additional 0.2 percent. Further, because most of the productivity benefits occur in the next several decades, when the labor force grows slowly, consumption remains above its initial level throughout the transition path to the new steady state.

\section{Demographic Change and Fiscal Policy}

The preceding section suggests that, other things being equal, the optimal response to recent and projected demographic changes is a

48. We use the support ratio defined with the earnings-weighted labor force and needsweighted consumption measure. We also assume unit elasticities of substitution in production and consumption. 
decline in the national saving rate. The implications for fiscal policy depend upon how the private saving rate responds to demographic changes. Tax-smoothing considerations may also imply particular patterns of optimal fiscal policy. This section examines these issues.

The effect of the population's aging on private saving has been the subject of a number of analyses, but no firm conclusion has yet emerged. From the standpoint of the life-cycle hypothesis, slowing population growth and an aging society should be associated with reductions in the private saving rate. As the aged share of the population increases, the ratio of dissavers to savers rises and so the private saving rate falls. David Weil has recently pointed out that this effect may be reinforced by an increase in expected bequests per member of the adult population..$^{49}$ On the other hand, many analysts have argued that the maturing of the baby boom generation will raise personal saving because people borrow when young and save as they approach middle age. Increases in personal saving may also result from people having fewer children.

Summers and Carroll explore the impact of demographic changes on saving behavior by assuming constant age-specific saving rates. ${ }^{50}$ Figure 17 uses the age-specific saving rates from their analysis, as well as Social Security Administration population forecasts, to project personal saving rates over the next 30 years. The results suggest that the maturing of the population will be associated with a small increase in saving rates during the next three decades. Calculations by Alan Auerbach and Laurence Kotlikoff reach similar conclusions. ${ }^{51}$

A near-term increase in private saving provides a further reason why an economy with an initially optimal saving rate should loosen fiscal policy in response to changing demographic conditions.

There is, however, a different argument for a tight fiscal policy. Projected demographic changes imply significant fluctuations in the level of government spending over the next century, since transfers to the

49. Weil (1989).

50. Summers and Carroll (1987).

51. Auerbach and Kotlikoff (1989). Both sets of calculations are flawed in ignoring pension saving, which may change as the age structure of the population changes. They also take no account of changes in the number of children or in the number of people supporting aged parents, although these factors may affect age-specific saving rates. David Weil (1990) uses aggregate data on OECD countries to study saving, recognizing these effects. His results suggest that private saving in the United States may rise about 1 percent in the next decade as a result of demographic factors. 
Figure 17. Projected Private Saving Rate, United States, 1990-2065 ${ }^{\mathrm{a}}$

Saving rate (percent)



Source: Summers and Carroll (1987); Board of Trustees of the Federal Old-Age and Survivors Insurance and Disability Insurance Trust Funds (1988).

a. The calculations assume that the saving rate is held constant by age.

elderly are much larger than those to any other group. Efficiency considerations argue for higher current taxes to fund foreseeable increases in government outlays. Because the deadweight loss of taxation increases with the square of the tax rate, financing the anticipated rise in government outlays on a pay-as-you-go basis, with lower tax rates during the next few decades and higher ones in the middle of the next century, entails a larger deadweight burden than a constant tax rate policy. ${ }^{52}$ This argument parallels the traditional justification for using debt to finance wars and other transitory shocks to government spending.

To evaluate the empirical significance of tax-smoothing considerations, we begin by describing the age-specific pattern of government outlays. We then present a simple framework for evaluating the efficiency

52. Barro (1979) describes the "tax-smoothing" view of optimal government financial policy. 
Table 8. Per Capita Government Spending, by Age, United States, 1989 1989 dollars

\begin{tabular}{lcccc}
\hline & $\begin{array}{c}\text { Social } \\
\text { security } \\
\text { and } \\
\text { disability }\end{array}$ & $\begin{array}{c}\text { Health } \\
\text { care }\end{array}$ & Education & Total \\
\hline $0-4$ & 132 & 872 & 674 & 1,678 \\
$5-14$ & 132 & 690 & 3,353 & 4,175 \\
$15-19$ & 132 & 298 & 2,930 & 3,360 \\
$20-24$ & 16 & 298 & 1,112 & 1,426 \\
$25-44$ & 83 & 298 & 233 & 614 \\
$45-64$ & 811 & 218 & 84 & 1,113 \\
65 and over & 6,138 & 3,526 & 84 & 9,748 \\
Total & 925 & 824 & 873 & 2,622 \\
\hline
\end{tabular}

Sources: Social Security Administration (1987); Waldo and others (1989); Board of Trustees of the Federal Supplementary Medical Insurance Trust Fund (1988). For details regarding construction of the data, see notes to table 9.

gains from tax smoothing and report suggestive calculations. These findings imply relatively small efficiency improvements-on the order of 1 percent of one year's GNP-from stabilizing tax rates throughout the next half-century.

\section{Age-Specific Patterns of Government Spending}

Governments spend different amounts on individuals of different ages. Outlays on education, for example, benefit primarily children, while the elderly are the principal beneficiaries of most government spending on health care and social security. Even without changes in the structure of government programs, demographic shifts can therefore affect the level of government spending.

Table 8 presents age-specific government expenditure patterns for the United States, focusing on the three largest social expenditures: social security, health care, and education. The first column shows spending on Old-Age and Survivors and Disability Insurance. Virtually all such expenditures are directed to individuals aged 65 or over, with average outlays in 1986 of $\$ 6,138$ per person. The second column shows analogous age-specific spending patterns for health care, with average expenditures per person aged 65 and over $(\$ 3,526)$ more than four times larger than outlays for any other age group. The third column reports 
Table 9. Projected Government Expenditures, United States, 1990-2060

Percent of GNP

\begin{tabular}{|c|c|c|c|c|c|}
\hline Year & $\begin{array}{c}\text { Social } \\
\text { security } \\
\text { and } \\
\text { disability }\end{array}$ & $\begin{array}{c}\text { Health } \\
\text { care }\end{array}$ & Education & Other & Total \\
\hline 1990 & 4.7 & 4.1 & 4.7 & 18.0 & 31.8 \\
\hline 2000 & 4.5 & 5.3 & 4.9 & 18.0 & 32.9 \\
\hline 2010 & 4.6 & 5.9 & 4.9 & 18.0 & 33.4 \\
\hline 2020 & 5.6 & 6.5 & 4.8 & 18.0 & 35.0 \\
\hline 2030 & 6.5 & 7.4 & 4.9 & 18.0 & 36.7 \\
\hline 2040 & 6.5 & 7.8 & 4.9 & 18.0 & 37.1 \\
\hline 2050 & 6.5 & 7.8 & 4.9 & 18.0 & 37.1 \\
\hline 2060 & 6.5 & 7.8 & 4.9 & 18.0 & 37.0 \\
\hline
\end{tabular}

Sources: Social security and disability spending are predicted from projected population growth rates. For the 1989 distribution of spending, we projected the year-end 1986 distribution from the Social Security Administration (1987) to 1989, using the GNP deflator. Spending at below retirement ages is the sum of OASDI payments to the disabled, payments to early retirees, and payments to surviving children and spouses. Spending on all persons below 20 years of age was treated as applying uniformly to the members of this group.

For health care spending, we combined four types of spending. We obtained 1987 estimates of Medicare and Medicaid per capita spending on the elderly for hospital care, physicians' services, nursing home care, and other personal health care from Waldo and others (1989). For the nonelderly population, we calculated government spending on each of these categories as the difference between the Division of National Cost Estimates, Office of Actuary, Health Care Financing Administration (1987) estimate of 1987 total government spending for that category and the implied spending on the elderly. This estimate includes both Medicaid spending for the nonelderly and medical care spending for government employees. We distributed this spending by age on the basis of Medicaid spending, as presented in Public Health Service (1989). All of the estimates were converted to 1989 dollars using category-specific projections of 1987-1990 inflation in Division of National Cost Estimates, Office of Actuary, Health Care Financing Administration (1987).

We forecast spending using estimates of inflation rates for the four categories of spending and projections of the age distribution of the population. Hospital care estimates are from the Board of Trustees of the Federal Supplementary Medical Insurance Trust Fund (1988). They imply a steady-state inflation rate above general inflation but below the growth rate of output. Inflation rates for the other three categories were projected to 2000 using the Division of National Cost Estimates, Office of Actuary, Health Care Financing Administration (1987) estimates, and were assumed to grow at the rate of hospital price inflation after that.

Finally, for age-specific spending on education, we obtained 1986 age-specific enrollment rates in school as well as the aggregate amounts spent on primary and secondary education, and higher education. We assumed that all persons under 17 who were enrolled in school were in primary and secondary schools, and all persons 18 and over who were enrolled were in higher education. Spending per person was then the weighted average of the population in each age group and the share of each age group in the two types of education. Our projections assume that education spending would grow at the rate of GNP growth, so that changes in the share of GNP devoted to education change only with changing numbers of young people.

the age profile of education spending. Per capita expenditures on schools for the younger cohorts are substantial, reaching $\$ 3,353$ a year for children between the ages of 5 and 14 . For the three programs combined, spending on the elderly is more than double that of any other group.

Demographic shifts can significantly alter government outlays. Table 9 reports projections of total government outlays as a share of GNP under the assumption that age-specific expenditure patterns remain at 1989 levels for the next 60 years. Primary government spending is assumed to equal a constant fraction of GNP. In these projections, 
government spending rises from 31.8 percent of GNP in 1990 to 37.0 percent of GNP in 2060, with nearly all the increase due to changes in medical expenditures and transfer programs to the elderly. Our taxsmoothing calculation assesses the efficiency gains from smoothing the time path of revenues needed to collect this variable expenditure stream.

\section{The Efficiency Gains from Tax Smoothing}

We evaluate the efficiency gain from tax smoothing by assuming that the deadweight burden of raising $\tau$ percent of national output in taxes is given by

$$
D W L_{t}=\epsilon \tau_{t}^{2} Y_{t} / 2 .
$$

The parameter $\epsilon$ depends on the elasticities of aggregate supply and demand and $Y_{t}$ is national income. ${ }^{53}$ The marginal deadweight loss per dollar of revenue raised is $\epsilon \tau_{\mathrm{t}}$. We calibrate $\epsilon$ by setting the marginal deadweight loss from raising one dollar equal to 30 cents, the upperbound estimate in Charles Ballard, John Shoven, and John Whalley's general equilibrium analysis of the U.S. tax system. ${ }^{54}$ Their calculation employs 1973 data, when federal and state-local taxation in the United States was 31 percent of GNP, and therefore implies $\epsilon \cong 1.0$.

We assume that a government planner seeks to minimize the present discounted value of the deadweight losses from taxation over a $T$ period horizon:

$$
V=\sum_{t=1}^{T}\left[\prod_{i=1}^{t}\left(1+r_{i}\right)^{-1}\right] \epsilon \tau_{t}^{2} Y_{t} / 2,
$$

where $r_{i}$ denotes the one-period nominal interest rate in period $i$. This minimization is subject to an intertemporal budget constraint linking taxes and spending as a share of GNP ( $\tau_{t}$ and $h_{t}$, respectively) with government debt as a share of GNP $\left(d_{t}\right)$. For each period, this constraint is:

$$
d_{t}=d_{t-1}\left[\left(1+r_{t}\right) /\left(1+\gamma_{t}\right)\right]+h_{t}-\tau_{t},
$$

53. If governments set taxes to minimize deadweight loss, the marginal deadweight burden per revenue dollar should be equal across tax instruments. The aggregate tax-toGNP ratio is then a simple proxy for the level of tax burdens. This convenient assumption neglects the voluminous public finance literature suggesting that marginal deadweight losses vary across tax instruments.

54. Ballard, Shoven, and Whalley (1985). 
where $r_{t}$ is the interest rate and $\gamma_{t}$ is the rate of output growth.

Summing this forward yields a budget constraint of the form:

$$
\sum_{t=1}^{T} \tau_{t} \delta_{t}=\sum_{t=1}^{T} h_{t} \delta_{t}+d_{0}-d_{T} \delta_{T}
$$

where $\delta_{t}=\prod_{s=1}^{t}\left(1+\gamma_{s}\right) /\left(1+r_{s}\right)$. Minimizing equation 20 subject to equation 22 yields first-order conditions of the form

$$
\epsilon \tau_{t}=\lambda,
$$

so the optimal policy calls for equal tax rates in each period.

In the case where $r_{t}=\gamma_{t}$, the benefits of tax smoothing take a particularly simple form. The budget constraint is

$$
\sum_{t=1}^{T} \tau_{t}=\sum_{t=1}^{T} h_{t}+d_{0}-d_{T}
$$

If, further, $d_{T}=d_{0}$, then with a pay-as-you-go policy, taxes just cover government spending: $\tau_{t}=h_{t}$. Under the constant period-by-period debt-to-GNP policy, the deadweight loss is

$$
D W L_{1}=\left(Y_{0} \epsilon / 2\right) \Sigma h_{t}^{2} .
$$

The constant tax rate satisfying the government budget constraint is just the average value of government spending, so that

$$
D W L_{2}=Y_{0} \epsilon / 2 \cdot T\left(\sum h_{t} / T\right)^{2} .
$$

Thus, the relative deadweight loss from the optimal tax-smoothing policy is:

$$
D W L_{2} / D W L_{1}=\left(\sum h_{t} / T\right)^{2} /\left(\sum h_{t}^{2} / T\right) .
$$

For the expenditure path in table 9, the deadweight loss reduction in equation 27 is 0.3 percent.

The incremental deadweight loss from time-varying tax rates depends on the precise time path of taxes, hence on the government's choice of debt policy. We consider two such policies. The first assumes a constant debt-to-GNP ratio in every year, and the second assumes a constant primary surplus (equal to its value in 1989 of 0.5 percent of GNP) in each year.

Table 10 presents our estimates of the efficiency gains from tax smoothing. The upper panel presents results assuming a constant debt- 
Table 10. Efficiency Gains from Smoothing Taxes, United States, 1990-2050 ${ }^{\mathrm{a}}$

Percent

\begin{tabular}{|c|c|c|c|c|c|}
\hline \multirow[b]{2}{*}{ Tax rate } & \multicolumn{4}{|c|}{ Year } & \multirow{2}{*}{$\begin{array}{l}\text { Average } \\
\text { deadweight } \\
\text { loss as } \\
\text { percent of } \\
\text { average } \\
\text { GNP }\end{array}$} \\
\hline & 1990 & 2010 & 2030 & 2050 & \\
\hline \multicolumn{6}{|c|}{ Constant debt-GNP ratio } \\
\hline Variable rate & 32.6 & 33.5 & 36.8 & 37.1 & 6.23 \\
\hline Constant rate & 35.3 & 35.3 & 35.3 & 35.3 & 6.22 \\
\hline \multicolumn{6}{|c|}{ Constant primary surplus ${ }^{\mathfrak{c}}$} \\
\hline Variable rate & 32.3 & 33.9 & 37.2 & 37.6 & 6.52 \\
\hline Constant rate & 35.7 & 35.7 & 35.7 & 35.7 & 6.51 \\
\hline
\end{tabular}

Source: Authors' calculations based on sources described in table 9 .

a. For each spending category, total government expenditures are projected to 2060 , as described in table 9 . The two cases are described in more detail in the text.

b. Constant debt-GNP ratio is fixed at 1989 level of 50.2 percent.

c. Constant primary surplus assumes that a federal and state-local surplus equals its 1989 share of GNP throughout 1990-2000.

to-GNP ratio, fixed at its 1989 level of 50.2 percent. In this case the payas-you-go tax rate rises from 32.6 percent of GNP in 1990 to 37.1 percent by 2050 . The average deadweight loss from this policy, shown in the last column, is 6.23 percent of the average value of GNP. The constant tax rate that achieves the same debt-to-GNP ratio of 50.2 percent in 2050 is 35.3 percent. Under this plan, taxes would rise by 3 percent of GNProughly $\$ 150$ billion-in 1990 . Despite this large change in the debt trajectory, however, the change in excess burden is small. The average value of deadweight loss is 6.22 percent of average GNP when tax rates are smoothed. The improvement in deadweight loss averages 0.017 percent of GNP annually, or less than $\$ 1$ billion a year in 1990 dollars. The change in the present value of deadweight losses between 1990 and 2060 equals 1.1 percent of $1990 \mathrm{GNP}$, or approximately $\$ 55$ billion.

The lower panel in table 10 shows parallel calculations assuming the combined federal and state-local primary surplus equals its 1989 share of GNP value throughout the 1990 to 2050 period. The results indicate that the average excess-burden-to-GNP ratio under this scenario is 6.52 percent, compared with 6.51 percent if the tax rate is smoothed. The difference between these two efficiency costs is similar to that in our first case, 0.017 percent of GNP. Plausible variations in our assumptions 
about the debt-to-GNP trajectory therefore do not appear to have large effects on the efficiency gains from tax smoothing. The general conclusion of these calculations is that there is only a weak tax-efficiency case for prepaying the costs of the future dependency burden.

\section{Conclusions}

Demographic changes currently in progress do not appear likely to worsen economic performance in the United States, at least during the next several decades. While increased dependency will reduce living standards by 5-10 percent in the long run, demographic changes will be beneficial over the next 20 years. In the short run, demographic change will have two important effects. First, slowing population growth will permit a smaller share of national output to be devoted to investment in plant, equipment, and housing. Second, the share of the population that is working will rise, largely as a result of the falling relative population of children. These positive effects of demographic change may be reinforced by increased foreign capital inflows and accelerating technical change as firms respond to an increasing scarcity of labor.

Recent and prospective demographic changes do not appear to warrant increasing the national saving rate. These changes increase wealth in the short run, reduce the rate of return to saving, and attract foreign capital. Holding all else equal, their net effect would be a reduction in the optimal national saving rate. Nor do tax-smoothing factors represent an important argument for trying to prepay the government's prospective liability to support a dependent population. There is little efficiency loss in following a pay-as-you-go policy with variable tax rates.

Our conclusion departs from analyses, such as that of Henry Aaron, Barry Bosworth, and Gary Burtless, that recommend accumulation of a large social security trust fund to bolster U.S. national saving. ${ }^{55}$ These positions are not necessarily inconsistent, however. A first line of reconciliation would hold that apart from demographic considerations, American national saving is much too low right now and that the social security trust fund provides a politically convenient way of reducing the 
federal government's absorption of private saving. ${ }^{56}$ The decline in the private saving rate from an average of 7.1 percent during the 1970s to about 3 percent during 1986-89 is greater than what our analysis suggests can be justified by demographic factors. There are even some reasons for advocating an increase in the U.S. national saving rate to levels above those observed historically, particularly in light of the emerging need for capital in Eastern Europe and the signs that saving is declining outside of the United States.

A second potential reconciliation of these views involves questions of optimal intergenerational redistribution. Some argue for using the social security trust fund to raise the national saving rate in order to avoid unfairly burdening our children. The primary thrust of this argument-that we need to prepare for the anticipated burden of increased dependency-is exactly what our support ratio calculations reject. This is because the dependency burden is remote, and because slower labor force growth means more rapidly diminishing returns to additional saving. Admittedly, our approach focuses on the economy's year-byyear consumption level, rather than the welfare of individual cohorts. It is therefore poorly suited to addressing arguments that certain cohorts will be greatly disadvantaged without additional capital accumulation. However, we do not find compelling the claim that our children will be unfairly burdened unless we increase capital accumulation today.

Two arguments militate against the intergenerational equity case for trust fund accumulation. First, if the aforementioned fears of inequity were correct, the appropriate response should be an adjustment in the level of prospective intergenerational transfers, not a change in capital accumulation policy. Just as concerns about the income distribution at a particular time are better addressed through transfer policies than through changes in the mix of products produced, transfers are the right way to respond to concerns about intergenerational equity. ${ }^{57}$

Second, other considerations operate to make the baby boom generation less well off than its successors. The baby boomers systematically lose because of their large cohort size. During their working years, wage growth is slow because of low capital-labor ratios. During their retirement years, the number of potential purchasers of capital will fall, thereby

56. See, for example, Hatsopoulos, Krugman, and Summers (1988).

57. This is the central point made by Calvo and Obstfeld (1988). 
reducing the rate of return on saving. ${ }^{58}$ Moreover, given productivity growth, the next generation will be considerably more affluent than the current one. If slower population growth or foreign capital inflows accelerate this tendency, the case for intergenerational redistribution is reduced. Even with our estimates of the path of optimal consumption, along which a declining support ratio reduces consumption, the lifetime utility of a person who lives for eighty years rises for those born from 1990 until 2020. Only after 2020 does the lifetime utility of new cohorts fall below that of those who lived before the demographic change.

Our aggregate analysis cannot resolve policy debates about raising the birth rate or increasing immigration, since these debates often focus on microeconomic effects and distributional consequences. Moreover, there is a fundamental political difficulty of deciding "who is us." How should the welfare of immigrants be treated in deciding whether or not to accept more of them? How should the utility of an otherwise unborn child be treated? Policy recommendations are impossible without a clear philosophical resolution of these questions.

Our analysis does, however, cast some doubt on the view that in narrow economic terms, higher fertility is helpful in reducing the burden of dependency in old age. Dependency at the beginning of the life cycle is between 50 percent and 100 percent as costly as dependency at the end of the life cycle. It also comes 60 years earlier. Furthermore, the weak available evidence suggests that slower population growth is more likely to raise than to reduce productivity growth.

For the set of issues captured by our analysis, there is a stronger case for increased immigration as a way of reducing dependency. Most immigrants arrive as young adults and so begin working without being dependents first. To the extent that they immediately start paying taxes for the support of the elderly, they may increase economic welfare of the preexisting population, even if they are ultimately eligible for transfer payments in old age.

We have only scratched the surface in assessing the macroeconomic implications of demographic change. Among the main priorities for future research, we would include the following. First, any effects of

58. Mankiw and Weil (1989) predict that real house prices will fall by almost 50 percent over the next 20 years because of demographic changes. While their results may overstate the coming decline, even small reductions in house prices would transfer large amounts of wealth to people who are very young today. 
demography on the rate of technical change are likely to dwarf its other consequences. It would be valuable to refine our estimates by considering data spanning longer periods and by experimenting with alternative control variables. Second, how demographic changes affect private saving remains uncertain. Investigating the international experience on this question seems worthwhile, particularly if long-term data can be located. Third, our calculations have assumed that the nonmedical care needs of the elderly are equal to those for the nonelderly. Whether this assumption is correct, and whether it will remain correct as the aged population ages, needs to be investigated. Fourth, it would be useful to analyze more systematically the impact of demographic changes on the welfare of different cohorts. This would require a life-cycle analysis of the questions we address with an infinite horizon setting. ${ }^{59}$

It would also be useful to explore the microeconomic implications of changing demography. For example, our aggregation of capital may well be inappropriate if demographic change alters the relative demands for housing and nonhousing capital. Similarly, demographic changes may have important implications for the labor market position of aged workers and for the relative demands for workers in different occupations.

Further research on these and other related topics is likely to refine the conclusions about demographic change reached here. We doubt that it will alter our primary conclusion that demographic change provides opportunities as well as challenges.

59. Auerbach and Kotlikoff (1987) and Auerbach and others (1989) use a life-cycle model to consider demographic issues, but they assume counterfactually that consumers actually vary their saving rates as the model would predict and do not use the model for normative analysis. 


\section{Comments and Discussion}

George A. Akerlof: The authors document the dramatic demographic changes that have been taking place in the United States since 1940: the steep increase in fertility in the 1940s and 1950s followed by the sharp decline in fertility in the 1960s. ${ }^{1}$ Although the ratio of elderly to the working population is projected to decline over the next two decades while the baby boomers remain active in the work force, large increases in this ratio are projected after 2010 when the baby boomers become retirees. The authors explore whether these demographic changes are cause for concern, focusing especially on the adjustments that should occur in national saving rates.

Their paper shows, convincingly in my opinion, that decreased fertility rates are not a reason for increased national saving even though lower fertility eventually causes an increase in the ratio of the retired to the working population. In the simple Solow model of economic growth, the change in an economy's capital-labor ratio at a point in time is the difference between saving per worker and "capital-widening" requirements per worker; the capital-widening requirement per worker is the investment per worker needed to equip new entrants to the work force with the same capital as existing workers. A decline in fertility, other things equal, lowers the economy's capital-widening requirements and increases the growth rate of the capital-labor ratio. Intuitively, the desirability of adding to society's stock of capital depends on the gap between the marginal productivity of capital and society's rate of time preference. With the saving rate fixed, a decline in fertility promotes "capital deepening" (it raises the growth rate of the capital-labor ratio) that, in turn, lowers the marginal productivity of capital relative to the

1. These comments were prepared jointly with Janet Yellen. 
rate of time preference; as a result, the optimal saving rate is reduced. Optimal saving is lower because, with decreased fertility rates, there is less need for investment to equip a growing work force.

This paper seems to fly in the face of conventional wisdom, which argues that demographic trends are one reason why U.S. saving is inadequate. According to a common argument, the increases in fertility during the 1940s and 1950s necessitate an increase in saving to provide for the baby boomers' retirement. In contrast, the authors argue that current demographic trends do not necessitate higher saving.

Appearances to the contrary, these two approaches are not mutually inconsistent. The two points of view are analyzing the same phenomenon from different time perspectives. The baby boom-baby bust demographic cycle, which the United States has experienced, consisted of an increase in fertility starting in the 1940s, followed by a decline in fertility beginning in 1960 . The demographic changes that began in 1940 optimally called for an increase in the saving rate (to appropriately equip the baby boomers with capital during their working years) followed by a decrease in the saving rate when the baby boom ended and declining fertility lowered capital-widening requirements.

According to the conventional view, saving did not increase as it should have when fertility increased, perhaps because of institutional factors such as social security and retirement plans whose benefits are directly linked to social security. Because the saving rate apparently did not rise in response to the fertility increase, it should rise now. In contrast, the authors, with a different starting point, ask how saving should respond to recent and anticipated demographic changes. Their answer is that, other things being equal, saving rates should decline now because declining fertility rates justify a decline in savings. If the insights of these two views were combined, one might conclude that if the saving rate had increased in response to the increase in fertility in the 1940s and 1950s as it should have, demographic factors beginning in 1960 and projected into the next century would optimally call for declining saving. But because the saving rate did not increase when it should have, in response to earlier demographic trends, it may be unwise to lower saving rates now in response to current and projected future trends. Properly interpreted, I therefore agree with the authors' assertion that 'other things being equal, the optimal policy response to recent and anticipated demographic changes is almost certainly a reduction rather than an 
increase in the national saving rate." But I also agree with the popular wisdom that the as yet inadequate response to the baby boom, which began in the 1940s, partly accounts for the inadequacy of the current capital stock.

The authors tell us: do not worry about the future dependency of the baby boomers. If you had saved a great deal in response to the baby boomers (as the planner would have in their model), now is the time for an increase in consumption. However, most peoples' worry is the opposite: they worry that we have not saved in response to the baby boom and, therefore, that saving should increase now while some time remains to prepare for the dependency bulge.

An analogy is apt. A traveler leaves Chicago bound for Cedar Rapids. He notes that his plane is traveling east. He tells the stewardess about his anxiety, saying that Cedar Rapids is west of Chicago and the plane is heading in the wrong direction. The stewardess is reassuring. She tells him that if he had begun his trip in Salt Lake City, where, on her assumptions, he should have started it, then he should be headed east, as the plane is currently going.

The correct moral to draw from the authors' paper is subtle. They have rightly reassured us that the consequences of our profligacy are not as dire as imagined, since the baby busters will require relatively little investment to satisfy capital-widening requirements.

The authors also examine the implications of population aging in the context of an explicit open-economy model. As they show, the trade partners of the United States will experience increases in dependency that are even more pronounced than those in the United States. Moreover, the near-term decline in dependency projected for the United States will not occur abroad. According to a naive view, these developments abroad are cause for concern. The United States is now highly dependent on foreign saving to finance its current spending. If saving abroad falls as dependency there increases, foreign lending may dry up, resulting in rising interest rates and a declining dollar. The authors point out the flaw in this naive scenario. The demographic changes that are occurring alter not only optimal consumption but also optimal investment. Over the next several decades, investment needs will decline more quickly in other countries than in the United States. In the absence of international capital flows, the return to investment should fall abroad and rise in the United States. In response to this differential, international 
capital flows into the United States should increase, not decrease. Taking into account the possibility of international borrowing and the likelihood that other countries will wish to export more, not less, capital strengthens the authors' conclusion that, other things being equal, saving need not rise now.

The authors advance two reasons for their view of the relation between the growth and age of the labor force and productivity growth. First, workers of different ages may contribute differentially to technological innovation. This is an age-embodied model of technological change. Second, diminished labor force growth may result in labor force scarcity that raises wages and results in labor-saving technological progress. The authors produce evidence that rapid labor force growth is negatively associated with rapid productivity increase and positively associated with the average age of the labor force in cross-section regressions. How much support this gives to their model of technological progress is hard to say. The authors' regressions omit wages. Furthermore, a cause common to both may yield a relation between productivity growth and labor force growth and population age but in no way imply a causal relation between the demographic factors and technological change. Following Max Weber, to give one example, Protestantism is responsible not only for the capitalist ethic and rapid innovation but also for low fertility. Thus productivity change and demographic change may have the same root cause without any implication that one causes the other. The authors' fixed-effects regression controls for intercountry cultural differences and potentially answers the objection that persistent cultural differences across countries account for the relation between productivity growth and fertility. The slope of this regression shows that as OECD countries (not including the United States) switched from high to low fertility, the rate of productivity growth rose. But it is not fully convincing that the relationship is causal rather than coincidental. Third, in a cleaner test, output per unit input, the Solow residual, would be chosen rather than productivity as the dependent variable.

In the final section of the paper the authors address whether taxes should be raised now in anticipation of higher burdens of government expenditure as the population ages. The paper compares the relative merits of a tax-smoothing strategy, in which taxes would be increased now, before dependency ratios increase, and of a pay-as-you-go policy of raising taxes later. As table 9 shows, the required increase in tax rates 
under a pay-as-you-go policy will be substantial-amounting to approximately 4.5 percent of GNP. Thus, in the absence of tax smoothing, future generations will have to pay a significantly higher portion of their income for social security and medicare benefits. An advantage of tax smoothing over pay-as-you-go is the lower deadweight burdens from taxation. According to Barro, an optimal tax policy would smooth taxes to minimize deadweight loss. Although the authors agree that tax smoothing is more efficient than a pay-as-you-go policy, they reassure us that little will be lost if the government waits to raise taxes until the dependency ratio actually increases. Their calculations show that the efficiency loss from pay-as-you-go is small even with a 30 percent deadweight loss associated with the marginal dollar of revenue.

Although I agree with the analysis, as far as it goes, I find the taxsmoothing issue one of misplaced emphasis. There is more at stake than aggregate efficiency considerations in the tax now-tax later debate. Tax policy matters both to income distribution between generations and also to aggregate capital accumulation. In their simulations, with tax smoothing, early generations would be roughly $2 \frac{1}{2}$ percent poorer and later generations would be $2 \frac{1}{2}$ percent richer. A pay-as-you-go policy benefits the current generation, but inflicts significant, avoidable burdens on our children. This assumes, of course, that Ricardian equivalence does not hold, for under Ricardian equivalence, the timing of tax collections is irrelevant to intergenerational income distribution, and thus efficiency is the sole appropriate concern of policy. In a Ricardian world, if taxes are imposed later rather than sooner, we will simply bequeath our children correspondingly additional wealth.

As the authors implicitly recognize, in the absence of Ricardian equivalence, the tax policy that is selected to finance a given program of government expenditures to the aged affects the pattern of capital accumulation. A tax-smoothing policy would lower consumption and promote greater capital accumulation now in advance of the increase in the dependency ratio; in contrast, a pay-as-you-go policy would result in lower capital formation now and later.The authors deal with capital accumulation and taxes separately, whereas, in fact, these two issues are not separable.

The authors also argue that optimal capital accumulation and income distribution among individuals living at the same time are separable issues. The Ramsey model, which is the basis for the recommendations 
concerning capital accumulation, is primarily concerned with the optimal intertemporal distribution of consumption among individuals alive at different times. The solution depends on the chosen social rate of discount, $\rho$, reflecting concern for those alive now relative to those who will be alive later. When considering tax and savings policy, the authors disregard the distribution of consumption among members of different generations alive at a given date, because they argue that these issues are separable. According to the authors, an optimal distribution of consumption between members of different generations who are alive at a given moment should be handled by age-specific transfer programs. However, practically, this entails either explicit or implicit adjustments to social security benefits. It is an odd exercise to project current levels of social security and other age-specific government expenditures and to advocate a pay-as-you-go system of taxation to fund these benefits while, at the same time, suggesting that if the income distributional consequences of these taxes are considered undesirable "the appropriate response should be an adjustment in the level of prospective intergenerational transfers. ..." Such an adjustment, in effect, would amount to offering retirees lower social security payments to avoid the higher taxes on workers that would be levied under the pay-as-you-go policy.

I would agree with James Tobin that "the overriding long-run issue about OASI is the balance between the tax contributions of the young and the benefits of the old." 2 The concern here lies not just with intergenerational income distribution, but also with the perceived fairness of the social security system. If the system is seen as unfair, younger generations may renege on the promises implicitly made to the older generations. And, perhaps more important, government will lose its moral authority to redistribute national income.

In conclusion, let me say that this is a very interesting paper. In particular, it reinforces the wisdom of development economists and family planners that fertility declines are almost always economically beneficial. In the case of the United States, although the fertility decline has posed unexpected problems for our pay-as-you-go social security system, still, it has resulted in less, rather than a greater, need for national saving.

2. Tobin (1988, p. 42). 
Martin Neil Baily: As I was reading this paper I was reminded of a phone call I received a few years ago from someone at the Readers' Digest. She was a fact checker and she was working on an article by a futurologist. He had claimed that GNP would be twice as large 30 years from now as it is today. Would I please say if this was correct. I took out my calculator and figured out that this represented a 2.5 percent a year growth rate, so I said it seemed fine to me. When I got off the phone, I reflected that forecasting long-term growth rates was a risky, perhaps even a foolish, business. The whole idea of fact-checking predictions seemed a little wacky. But as this paper makes clear, long-term forecasts are directly relevant to personal and policy decisions today. The optimal saving rate depends heavily on the expected rate of productivity growth over the long term. Such forecasting is necessary.

This paper is a tour de force in many ways. It provides a systematic attempt to apply the principles of optimal growth to a problem of empirical importance. It is comprehensive in taking into account not only changes in the work force but also the relation between the work force and the population, the different social demands of the young and the old, and the consequences of international capital flows. My comments will cover some points of detail and then look at a more basic concern.

First, in assessing the dependency ratio, the authors point out correctly that the rise in the number of old people will be offset by the decline in the number of young people. They take some account of the fact that old people use more resources than young, but perhaps not enough. The effect of many of the advances in medicine has been to allow old people to live longer. As Summers and Poterba know from their prior work, the biggest gains in reductions of death rates have been for those over 80 . If these trends in medical advance and longevity continue, they will have an impact on the effective dependency ratio. The study of long-term care by Alice Rivlin and Joshua Wiener has indicated that a tremendous increase in medical and nursing home care will probably be needed. ${ }^{1}$

The authors also take account of the increase in the time people are spending in retirement, but there too I wonder if the effect could have been understated. The resource cost of the growing cohort of elderly is 
likely to become very large indeed in the next century. My intuition says that we should prepare now for the social problems that this will create, and the authors' paper has not overcome this intuition.

Second, the argument is made that the gains from tax smoothing are not very great. This does not seem to fit with observed political behavior. Substantial political battles have been waged over tax rate changes roughly the same as the changes given here. The political consequences of a shift from taxes being 32 percent of income to 37 percent of income are likely to be substantial, particularly if the increase translates in practice into a 10 percentage point increase in the payroll tax. If overall deadweight loss were the only criterion by which to judge tax changes, then presumably we should consider the poll tax an exemplary tax. The marchers in Trafalgar Square who were throwing chairs, however, did not seem overly impressed by the small deadweight losses implied by Margaret Thatcher's poll tax.

Of course, much of the political debate over taxes turns on distributional issues, but supporting the elderly will be a distributional issue too, with the burden falling on workers and the benefits falling on retirees. If the Moynihan view that there is no need to accumulate a surplus in the social security trust fund prevails, today's debate on that issue is likely to reverberate in Congress 30 years from now: "Why should we impose these huge taxes on our workers today when the current beneficiaries refused to pay their share when they were working?" Presumably, cutting benefits to the elderly will be the other alternative.

Third, the open-economy simulations assume too much capital mobility. One can make a pretty good argument that there is perfect capital mobility for short-term government securities. But there certainly is not perfect mobility for factories or business capital generally. Flows of real capital, like real trade flows, are very sticky. It is certainly possible to finance our budget deficit with capital inflows, as we have discovered. And those inflows may also inflate property markets in Honolulu and Manhattan, but they do not do much for business capital formation or productivity. The portfolio choice that an economy makes is affected by the preferences of the owners of the capital and hence where the saving is coming from.

Fourth, there are better ways of capturing the impact of changing demographics on productivity than the regression approach used here. Estimates of age-earnings profiles used by Dale Jorgenson, Edward 
Denison, and others in their accounting studies of past growth to construct adjusted labor inputs could be used to simulate the effects on productivity of the projected demographic changes. ${ }^{2}$ It would also be better to start with the standard hypothesis that relative wages reflect relative marginal products and that the projected aging will raise future productivity as more workers move into their high-productivity years.

The attempt in the paper to estimate that demographic changes will have a big bang for the buck is not convincing. The hypothesis is not tested by starting with the standard alternate hypothesis, based on ageearnings profiles, and then seeing if the data suggest a significantly greater impact. Anecdotal evidence abounds that older workers find it harder to adjust to changes in technology.

Fifth, the authors do not comment on one demographic offset to the projected benefits of aging. John Bishop has investigated the hypothesis that general intellectual achievement is important to productivity and that boosting general intellectual achievement is what schooling does, at least up to the end of high school. ${ }^{3}$ Various measures of that achievement have shown declines beginning in the late 1960s. In an earlier paper, I argued that this decline in test scores could not have had a major effect on productivity in the 1970 s because of the small size of the cohort that had entered the labor force. ${ }^{4}$ Bishop suggests that the effects are becoming larger in the 1990s-the low-score rabbit is now moving into the middle of the labor force snake.

I turn now to the more general concern. I find it hard to put the paper's findings in context. The authors are looking for the partial effect of demographic changes on the optimal saving rate. That is obviously an interesting issue to look at, but it is hard to read the analysis without worrying that the U.S. economy is probably a long way from an optimal path of accumulation for other reasons, notably because of the growth slowdown, government dissaving, and life-cycle saving requirements.

My reading of the optimal growth literature of the 1960s is that it implied that the U.S. economy was saving too little. The optimality condition is that the rate of profit should equal the rate of growth plus a discount factor. Plausible rates of discount left the profit rate too high and hence the capital intensity of the economy too low. Taxes and risks

2. Denison (1985); Jorgenson, Gollop, and Fraumeni (1987).

3. Bishop (1989).

4. Baily (1981). 
are reasons why private decisions can lead to nonoptimal social outcomes.

These findings from the 1960s were being applied to an economy with relatively rapid growth. The productivity growth slowdown should have led to a substantial increase in the optimal level of saving, unless one believes that the slowdown is just temporary. The living standards of future generations are going to be much lower than we thought. If saving was already too low and has subsequently fallen sharply, and if the optimal rate of saving has risen because of the productivity slowdown, then we now have a huge gap between the actual rate of saving and the optimal rate. Even if the authors are correct that the partial effect of demographic change is to lower the optimal saving rate, their finding is cold comfort.

Turning specifically to the demographic issue, I did not understand a key element in the modeling. Once we take into account the human life cycle, the objective function of the optimal growth planner changes. The planner should not maximize the integral of discounted per capita utility times the number of people. The integral of the lifetime utility of each member of the population times the number of people would be a better concept. And I think that affects the conclusions. For example, compare two economies with different demographic compositions. The two economies might have different rates of growth of output and different intertemporal consumption patterns, but the lifetime utility of any individual could be the same in the two economies. And presumably the reverse situation could hold, where the aggregates look the same in two economies, but individuals have rather different lifetime utilities.

This issue of lifetime utility affects the concluding section of the paper, where the authors ask how their findings can be reconciled with the idea that the social security trust fund should build up a surplus to pay for the retirement of the baby boom generation. The place to start when deciding whether social security decisions are correct is to ask what rational far-sighted people would do if there were no social security. The life-cycle model says that individuals in their high-income years will save for retirement. That will surely translate into higher aggregate saving in periods like the current one when a large fraction of the population is in its high-income years.

The pure retirement element of the social security system is presumably based on the assumption that many people either do not make rational far-sighted decisions or lack self-discipline, and so the program 
forces them to save for their retirement. Then to mimic the rational private decision, the trust fund should now build up a surplus. Why does this not show up in the authors' results?

Without tinkering at length with the optimal growth conditions, I am not sure, but I think it is related to one of the things that Charles Schultze and I pointed to in a recent paper. ${ }^{5}$ The steady-state rate of growth of the U.S. economy has declined, and so the rate of profit is declining. The projected decline in the growth of the labor force will drive down the rate of profit further. The decline in the warranted rate of growth is driving the authors' conclusion that the optimal saving rate will decline. This result is very much a steady-state conclusion, however, and there is no guarantee that the same result should hold even over periods of several decades.

It is not clear from theory that a decline in the rate of profit should reduce saving by rational individuals, and it is not clear from empirical evidence that actual people do reduce saving when the rate of return declines. I would expect the life-cycle effect to dominate over the rate of profit effect so that the aggregate saving rate of rational savers would increase as the baby boomers hit their peak earnings years. If so, the social security trust fund should follow their lead.

Of course social security is not only a forced retirement program; it is also redistributive. And there the authors have a good point. The baby boomers have had it tough competing against their own large cohort. They are entitled to expect later generations to contribute to the support of the low-income elderly in the next century. The build-up of the trust fund should not try to do it all.

This is a provocative and important paper that questions a conventional wisdom about the appropriate way to respond to demographic changes. The model has not settled some important issues, but it is not wrong either. It raises legitimate questions about the level of saving we should expect or seek.

\section{General Discussion}

The paper's implications for national saving policy sparked a lively discussion. William Nordhaus praised the paper for raising the quality of the analysis about the effects of demographic trends on the national

5. Baily and Schultze (1990). 
saving rate. A number of other panelists expressed concern that the paper would be misunderstood and misused in the current policy debate over national saving. Gary Burtless emphasized that if the saving rate is too low to begin with, slower labor force growth should not be an argument for decreasing it further. Lawrence Summers agreed that it would be desirable to raise the national saving rate for a variety of reasons, but said the point of the paper is that demographic change is not one of them. Charles Schultze suggested simulating desired future saving using the assumption that the initial stock of capital is less than optimal. Although estimates of the marginal effects of population might be quite similar to those in the paper, such simulations would avoid the impression that policy should aim to reduce saving from current, suboptimal levels. Robert Gordon dissented from the widely held view that current national saving is too low. He noted that net private investment is close to the level necessary to maintain the capital-output ratio. The projected decline in the population growth rate and increase in private saving due to the change in the age distribution should mitigate any concerns that investment is being financed by a current account deficit. He also pointed out that the changes in per capita income resulting from different capital-output ratios are small compared with the uncertainty about the future growth in productivity. The real problem for policy, he contended, is the lack of public investment and the need to redistribute the peace dividend in that direction.

Various panelists questioned whether the results were robust with respect to certain changes in assumptions. While noting that the theoretical possibility that declining fertility might increase welfare was not new, Henry Aaron wondered whether the proposition would be valid for one country in a world economy. In particular, he did not regard the OECD as an adequate representative for the "rest of the world," and argued that the inclusion of non-OECD countries might well reverse the authors' presumption that the net supply of savings from abroad will increase. Albert Wojnilower agreed that non-OECD countries should be considered. Lawrence Summers noted that in light of the low returns on investment in the southern hemisphere, both historical and anticipated, that region was unlikely to be a user of saving.

Burtless doubted that the social-welfare function used in the paper captured the unpleasant trade-off between the consumption of different generations. He reasoned that, if our grandchildren were expected to 
enjoy real income twice as high as our own, it might be difficult to persuade us to make an additional consumption sacrifice today so that their incomes could be 2.1 times higher than our own. On the other hand, if we thought that our grandchildren would be barely better off-or even worse off-than we are, then many of us might be willing to make a sacrifice of current consumption in order to raise their living standards. Burtless suggested that a major argument for higher saving today is that we have become less optimistic about the income prospects of our grandchildren, primarily because of a sharp drop in productivity growth. The demographic shock of a higher dependency ratio, which is emphasized in the paper, is not the main reason for pessimism about future living standards. Hence, even if demographic concerns by themselves do not push us to raise current saving rates, other concerns push us in that direction. Edmund Phelps was curious how the optimal consumption time path would vary if it was calculated with successively lower intertemporal substitution elasticities. He speculated that, in the limit, current consumption might go down, not up. Thomas Juster wondered how the conclusions would be changed if the authors had used a utility function that was consistent with people's apparent preference for rising consumption over steady or declining consumption, even when faced with low real rates of return. Such preferences, if true, suggest that a path of first rising and then falling consumption is not optimal.

Several panelists criticized the paper's treatment of technological change. Nordhaus found unconvincing the cross-country comparisons suggesting that lower population growth causes higher productivity growth, because, he said, so many other factors can be at work. Phelps doubted that increased labor scarcity would lead to greater technological progress, and wondered why decreased capital scarcity would not have the opposite effect. Summers defended the use of cross-country comparisons, remarking that it would be hard to think of another natural experiment with which to search for these effects. Furthermore, to the extent that movements in some unobserved factor are responsible for the apparent correlation of productivity and fertility, there is no reason to think the same factor is not at work in the United States. At a minimum he felt that the cross-country comparisons defused any fear that a slowdown in dynamism would accompany a reduction in the population growth rate. Franco Modigliani, while finding it plausible that greater age is associated with higher levels of productivity, saw no reason it 
should lead to faster growth in productivity. Joseph Stiglitz observed that returns-to-scale effects in learning-by-doing and endogenous R\&D models could give the opposite effect, with lower labor force growth adversely affecting productivity.

Nordhaus suggested it would be more accurate to weight the nonmedical consumption of the elderly at about 80 percent of that of working people. He also conjectured that if subsequent generations consume fewer market goods but more leisure, then it may not be optimal to save less now. Summers noted that the procedure in the paper accommodates the possibility of increased leisure under the assumption that it requires no capital and is separable from ordinary consumption in the utility function. Nordhaus also thought it useful to distinguish three sources of slowing labor input: declines in fertility, reduced fraction of lifetime spent working, and the rise in the disability rate. Each of these sources would have a different effect on optimal saving behavior.

Several panelists discussed ways in which private sector saving and investment are likely to be affected by changed demographics. Modigliani noted that in the typical life-cycle model, when an economy grows less fast, it saves less. He conjectured that the demographic changes would automatically reduce private saving, perhaps even more than the authors believed optimal. Gordon noted that although slower population growth is likely to lower future housing prices, most of the effect of that reduction would be in smaller bequests to the young rather than lower consumption by the elderly. Phelps observed that the predicted reduction in investment could result in an employment problem because the capitalgoods sector is more labor intensive than the consumption-goods sector. Wojnilower observed that because the elderly will have more political power because of their larger share of the population, perhaps government policy itself will be directly influenced by the change in demographics. Gordon suggested two policy actions that offered solutions to the dependency problem. The first was raising the immigration-to-population ratio to the 1913 level. The second was allowing the retirement age to increase with life expectancy. 


\section{References}

Aaron, Henry J., Barry P. Bosworth, and Gary Burtless. 1989. Can America Afford to Grow Old? Paying for Social Security. Washington: Brookings. Auerbach, Alan J., and Laurence J. Kotlikoff. 1989. "Demographics, Fiscal Policy, and U.S. Saving in the 1980s and Beyond." Working Paper 3150. Cambridge, Mass.: National Bureau of Economic Research (October).

- 1987. Dynamic Fiscal Policy. New York: Cambridge University Press. Auerbach, Alan J., and others. 1989. "The Economic Dynamics of an Aging Population: The Case of Four OECD Countries. OECD Economic Studies 12: 97-130.

Baily, Martin N. 1981. "Productivity and the Services of Capital and Labor." BPEA, 1:1981, 1-50.

Baily, Martin Neil, and Charles L. Schultze. 1990. "The Productivity of Capital in a Period of Slower Growth." BPEA: Microeconomics, 1990, 369-406.

Ballard, Charles L., John B. Shoven, and John Whalley. 1985. "General Equilibrium Computations of the Marginal Welfare Costs of Taxes in the United States." American Economic Review 75: 128-38.

Bishop, John. 1989. "Is the Test Score Decline Responsible for the Productivity Growth Decline?" American Economic Review 79: 178-97.

Blanchard, Olivier J., and Stanley Fischer. 1989. Lectures on Macroeconomics. Cambridge, Mass.: MIT Press.

Barro, Robert J. 1979. "On the Determination of the Public Debt." Journal of Political Economy 87: 940-71.

Board of Trustees of the Federal Old-Age and Survivors Insurance and Disability Insurance Trust Funds. 1988. 1988 Annual Report. Washington: Social Security Administration.

- 1990.1990 Annual Report. Washington: Social Security Administration.

Board of Trustees of the Federal Supplementary Medical Insurance Trust Fund. 1988. 1988 Annual Report. Washington: Social Security Administration.

Borjas, George J. 1990. Friends or Strangers: The Impact of Immigration on the U.S. Economy. New York: Basic Books.

Calvo, Guillermo A., and Maurice Obstfeld. 1988. "Optimal Time-Consistent Fiscal Policy with Finite Lifetimes: Analysis and Extensions.' In Economic Effects of the Government Budget, edited by Elhanan Helpman, Assaf Razin, and Efraim Sadka. Cambridge, Mass.: MIT Press.

DeLong, J. Bradford. 1988. "Productivity Growth, Convergence, and Welfare: Comment." American Economic Review 78: 1138-54.

Denison, Edward F. 1985. Trends in American Economic Growth, 1929-82. Washington: Brookings. 
Division of National Cost Estimates, Office of the Actuary, Health Care Financing Administration. 1987. "National Health Expenditures, 19862000." Health Care Financing Review 8(Summer): 1-36.

Freeman, Richard B. 1988. "Labour Market Institutions and Economic Performance." Economic Policy 6: 63-80.

Habakkuk, H. J. 1962. American and British Technology in the Nineteenth Century. Cambridge, England: Cambridge University Press.

Hatsopoulos, George N., Paul R. Krugman, and Lawrence H. Summers. 1988. “U.S. Competitiveness: Beyond the Trade Deficit." Science, July 15: 299307.

Jorgenson, Dale, Frank M. Gollop, and Barbara M. Fraumeni. 1987. Productivity and U.S. Economic Growth. Cambridge, Mass.: Harvard University Press.

Lazear, Edward P., and Robert T. Michael. 1980. "Family Size and the Distribution of Real Per Capita Income." American Economic Review 70: 91-107.

Mankiw, N. Gregory, and David Weil. 1989. "The Baby Boom, the Baby Bust, and the Housing Market." Regional Science and Urban Economics, 235-58.

Mankiw, N. Gregory, David Romer, and David Weil. 1990. "A Contribution to the Empirics of Economic Growth" (February).

Organization for Economic Cooperation and Development. 1988. Aging Populations: The Social Policy Implications. Paris: OECD.

Poterba, James M., and Lawrence H. Summers. 1987. "Public Policy Implications of Declining Old-Age Mortality." In Work, Health, and Income among the Elderly, edited by Gary Burtless. Washington: Brookings.

Public Health Service. 1989. Health United States 1988. Hyattsville, Md.: Department of Health and Human Services (March).

Rivlin, Alice M., and Joshua M. Wiener. 1988. Caring for the Disabled Elderly: Who Will Pay? Washington: Brookings.

Romer, Paul M. 1990. "Capital, Labor, and Productivity." BPEA: Microeconomics 1990, 337-67.

Schneider, Edward L., and Jack Guralnik. 1990. "The Aging of America: Impact on Health Care Costs." Journal of the American Medical Association 263 (May 2): 2335-40.

Simon, Julian L. 1981. The Ultimate Resource. Princeton: Princeton University Press.

Social Security Administration. 1987. Social Security Bulletin, Annual Statistical Supplement. Washington (December).

- 1989. Social Security Area Population Projections: 1989. Actuarial Study 105. SSA Pub. No. 11-11552. Washington (June).

Summers, Lawrence H., and Chris Carroll. 1987. "Why Is U.S. Saving So Low?" BPEA, 2:1987, 607-35.

Summers, Robert, and Alan Heston. 1990. "The Penn World Table (Mark 5): 
An Expanded Set of International Comparisons." Quarterly Journal of Economics (forthcoming).

Tobin, James. 1988. "The Future of Social Security: One Economist's Assessment."' In Social Security: Beyond the Rhetoric of Crisis, edited by Theodore R. Marmor and Jerry L. Mashaw. Princeton: Princeton University Press.

Waldo, Daniel R., and others. 1989. "Health Expenditures by Age Group, 1977 and 1987." Health Care Financing Review 10 (Summer): 111-20.

Wattenberg, Ben J. 1987. The Birth Dearth. New York: Pharos Books.

Weil, David. 1989. "Age and Saving in Micro and Macro Data." Harvard University.

1990. "Prospects for Saving in the OECD over the Next 35 Years." Harvard University. 